\title{
A model for the thermodynamics of and strengthening due to co-clusters in Al-Mg- Si based alloys
}

\author{
M.J. Starink ${ }^{1}$, L.F. $\mathrm{Cao}^{2}$ and P.A. Rometsch ${ }^{2}$ \\ ${ }^{1}$ Materials Research Group, Engineering Sciences, \\ University of Southampton, Southampton S017 1BJ, UK; \\ ${ }^{2}$ ARC Centre of Excellence for Design in Light Metals, \\ Monash University, VIC 3800, Australia
}

\begin{abstract}
An expanded model for the thermodynamics of co-clusters and their strengthening is presented, and the model is applied to predict co-cluster formation and strengthening in Al$\mathrm{Mg}$-Si alloys. The models are tested against data on a wide range of Al-Mg-Si alloys aged at room temperature. The strengthening due to co-clusters is predicted well. The formation of the co-clusters is studied in an $\mathrm{Al}-0.5 \mathrm{at} \% \mathrm{Mg}-1 \mathrm{at} \% \mathrm{Si}$ alloy using three-dimensional atom probe analysis. The results correspond well with the model. It is shown that in general, (shortrange) order strengthening due to co-clusters will be the main strengthening mechanism in these alloys. Apart from the co-clusters, Si clusters also form, but due to their low enthalpy of formation, they contribute little to the strength.
\end{abstract}

Keywords: Natural ageing; nanostructure; modelling; thermodynamics; short range ordering

\section{Introduction}

In the past 15 years it has become clear that a number of heat treatable ternary and higher order alloys are strengthened by the presence of co-clusters. Particularly 3D atom probe (3DAP) studies have allowed the identification of co-clusters with as few as 10 atoms or less in alloys such as in maraging Fe-20Ni-1.8Mn-1.5Ti-0.59Al steel [1], Fe-C-Mn-Si steels with additions of $\mathrm{Nb}, \mathrm{Al}$ and $\mathrm{Mo}$ [2], Al-Zn-Mg(-Cu) [3], Al-Mg-Ag [4], Al-Mg-Si [5,6,7,8] and $\mathrm{Al}-\mathrm{Cu}-\mathrm{Mg}$ based alloys [9,10,11] (in several aluminium alloys the term Guinier-Preston (GP) zone has been associated with these clusters). Nuclear Magnetic Resonance (NMR) [12,13], X-ray absorption spectroscopy (XAS) [14] and positron annihilation lifetime spectroscopy (PALS) studies $[15,16]$ ) have been applied to reveal changes at the atomic level due to the formation of co-clusters.

In Al-Mg-Si alloys, ageing at room temperature after solution treatment leads to an increase in strength and hardness, and a plateau in hardness/strength is generally achieved after several days of natural ageing [17]. Once the plateau is reached, the hardness will remain constant for years. It has been clearly shown in several works that apart from cluster formation and changes related to vacancies, no other microstructural changes occur $[5,6,7,8,18]$. It is hence 
clear that room temperature hardening is due to the formation of clusters and/or co-clusters. The main precipitate that forms during artificial ageing at temperatures of around 125 to $200^{\circ} \mathrm{C}$ is the $\beta^{\prime \prime}$ precipitate $[19,20]$, which is responsible for the peak in hardness during artificial ageing in commercial T6 tempers [19].

In 3DAP studies on ageing at room temperature, several features of clusters have been observed [6,7,8,18,21]. Following the application of cluster identification algorithms, the detected clusters are irregularly-shaped and have a wide range of sizes, typically from 2 to about 30 detected solute atoms. These clusters are too small to be resolved by conventional transmission electron microscopy (TEM). Larger co-clusters (sometimes referred to as coherent zones, or pre $\beta^{\prime \prime}[20]$ ), contain at least 30-100 detected solute atoms and are more spherically-shaped. The coherency strains around these zones enable them to be resolved by conventional TEM.

The motivation for the present work is twofold. Firstly, we want to investigate the basic mechanisms of cluster hardening to explain and predict the room temperature age hardening of Al-Mg-Si alloys. Secondly, we want to provide a basis for an improved understanding of the deleterious effect of room temperature ageing on subsequent artificial ageing in alloys with $\mathrm{Mg}_{2} \mathrm{Si}$ content in excess of $\sim 1 \mathrm{wt} \%$. The latter effect is very important as it limits the applicability of Al-Mg-Si in several applications, for instance, in the case of automotive body panels, where the paint-bake hardening response is impaired by pre-aging at room temperature. The objective of the present work is to present a model for the thermodynamics of and strengthening due to co-clusters in Al-Mg-Si based alloys, and to verify it by comparison with both new 3DAP experiments and data available in the literature. In this work, we have performed extensive 3DAP and age hardening investigations on an alloy with a $\mathrm{Mg}:$ Si ratio of 0.5 .
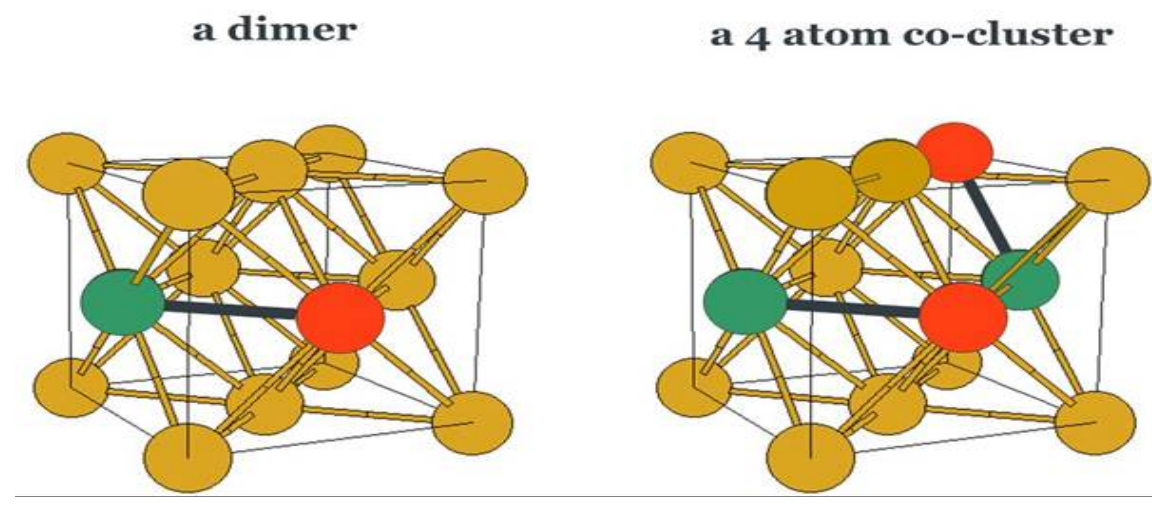

Fig. 1 Possible constellations of co-clusters in an fcc lattice: a dimer (a), one of many possible variants of a 4 atom cluster (b). 


\section{A model for the thermodynamics of and strengthening due to co-clusters}

In principle, a number of approaches for predicting the thermodynamics of and strengthening due to co-clusters may be pursued, based on the evolution of complex clusters and their interactions at various distances. We here aim to show that a simple near-neighbour interaction can be used to successfully model strengthening and the basic features of the clusters. Following [22], we will consider co-clusters to consist of units of near-neighbour dissimilar atoms, such as illustrated in Fig. 1a. (The near neighbour arrangement also occurs in the structure of the so-called pre $\beta^{\prime \prime}$ precipitates proposed in [20], which can be considered to be built up predominantly from near neighbour Mg-Si pairs in the fcc lattice with small changes in atoms positions.) In the first stage of model development we will assume that coclusters are dominant, and we will proceed to derive a full model for the thermodynamics of the system with co-clusters and the strength of an alloy containing co-clusters. Model extensions to include same atom clusters (particularly $\mathrm{Si}-\mathrm{Si}$ ) will be presented in Section 5.

\subsection{The thermodynamics of co-clusters}

For modelling the thermodynamics of the co-clusters one may consider the possibility of the co-clusters forming a range of possible constellations in the FCC lattice. Following experimental evidence which indicates that co-clusters can be as small as 2 to 4 atoms and that their Mg:Si ratio is close to 1 (see section 4.1), we will here extend a model for dimers that was first outlined in [22]. In the model we consider alloying elements A and B in a host metal $\mathrm{M}$, with the total number of the respective atoms in the system being $N_{\mathrm{A}}, N_{\mathrm{B}}$ and $N_{\mathrm{M}}$. The Gibbs free energy, $G$, of the system is approximated as:

$$
G=H_{o}-N_{c l} \Delta H_{A-B}-T S
$$

where $N_{\mathrm{cl}}$ is the number of A-B two-atom co-clusters, $H_{\mathrm{o}}$ is a reference enthalpy and $\Delta H_{\mathrm{A}-\mathrm{B}}$ is the enthalpy of formation of a two-atom co-cluster from the random solution, i.e. the enthalpy of the reaction in which one $\mathrm{A}$ atom and one $\mathrm{B}$ atom, originally in random solution, form an A-B two-atom co-cluster. The entropy of the system is thought to be dominated by the configurational entropy, which is proportional to the logarithm of the number of states $w$ in the system. The configurational entropy for the system with two-atom co-clusters like in Fig. 1a is given by:

$$
S=k_{B} \ln w=k_{B} \ln \left(\frac{N !}{\left(N_{M} !\left(N_{A}-N_{c l}\right) !\left(N_{B}-N_{c l}\right) !\right) \lambda_{2} N_{c l} !}\right)
$$

where $N=N_{\mathrm{A}}+N_{\mathrm{B}}+N_{\mathrm{M}}, k_{\mathrm{B}}$ is Boltzmann's constant and $\lambda$ is the coordination number of the cluster; for the dimer in Fig. 1a, $\lambda_{2}=12$ For equilibrium it holds that $\partial G / \partial N_{\mathrm{cl}}=0$. Performing this derivation using the latter two equations (using the Stirling approximation of $\ln N !=N \ln N$ $N$ ) then provides that at equilibrium the following holds: 


$$
c_{A} c_{B}=\exp (-2) \exp \left[\frac{-\Delta H_{A-B}}{R T}\right]
$$

where $c_{\mathrm{A}}$ is the solubility (i.e. the equilibrium molar fraction) of element $\mathrm{A}$ in the M-rich host lattice, and $c_{\mathrm{B}}$ is the solubility of element $\mathrm{B}$ in the M-rich host lattice. Thus the latter equation provides the metastable solvus of the co-cluster dimers.

We can extend this analysis to include larger co-clusters. For a system which contains coclusters in the form of a 4 atom A-B-A-B co-cluster, the Gibbs free energy, $G$, of the system can be approximated by considering that the enthalpy term contains the enthalpy due to two A-B dimers, $\Delta H_{\mathrm{A}-\mathrm{B}}$, plus the interaction enthalpy between these two dimers, $\Delta H_{\mathrm{AB}-\mathrm{AB}}$. Hence the free energy is given by:

$$
G=H_{o}-N_{c l}\left(2 \Delta H_{A-B}+\Delta H_{A B-A B}\right)-T S
$$

The entropy of this system is given by:

$$
S=k_{B} \ln w=k_{B} \ln \left(\frac{N !}{\left(N_{M} !\left(N_{A}-N_{c l} / 2\right) !\left(N_{B}-N_{c l} / 2\right) !\right) \lambda_{4}\left(N_{c l} / 2\right) !}\right)
$$

where $\lambda_{4}$ is the number of ways in which the 4 atoms co-cluster can be oriented in the lattice. From applying $\partial G / \partial N_{\mathrm{cl}}=0$, we can now obtain that at equilibrium:

$$
c_{A} c_{B}=\exp (-2) \exp \left[\frac{-\left(\Delta H_{A-B}+\Delta H_{A B-A B} / 2\right)}{R T}\right]
$$

In a similar way, we can approximate the free energy of larger clusters that are made up of units of A-B. In all cases, the solvus will be described by an expression of the form

$$
c_{A} c_{B}=\exp (-2) \exp \left[\frac{-\Delta H_{c l}}{R T}\right]
$$

where $\Delta H_{\mathrm{cl}}$ is the enthalpy change per A-B pair:

$$
\Delta H_{c l} \cong \Delta H_{A-B}+\frac{N_{c l a t}-2}{N_{\text {clat }}} \Delta H_{A B-A B}
$$

where $N_{\text {clat }}$ is the number of atoms in the cluster. The above shows that if $\Delta H_{\mathrm{AB}-\mathrm{AB}}$ is positive, the stability will increase if the number of atoms in the cluster increases. 
In practice it will be very challenging to predict $\Delta H_{\mathrm{AB}-\mathrm{AB}}$, and probably impossible to provide an experimental verification. Hence we will here simplify Eq. 8 by assuming $\Delta H_{\mathrm{AB}-\mathrm{AB}}<<\Delta H_{\mathrm{A}-}$ B. We will thus approximate $\Delta H_{\mathrm{cl}}=\Delta H_{\mathrm{A}-\mathrm{B}}$.

To calibrate this model for the thermodynamics we need to determine only one parameter, the enthalpy of formation of a (typical) cluster from the random solution, $\Delta H_{\mathrm{A}-\mathrm{B}}$. The method for determining this parameter, using the enthalpy change during a DSC experiment, is outlined in [22]. This procedure is here applied using DSC data on solution treated Al- $0.58 \mathrm{Si}-0.99 \mathrm{Mg}$ (at $\%$ ) and solution treated Al-0.79Si-0.91Mg (at\%) in $[18,23]$, which both show a clear exothermic effect between about 30 and $120^{\circ} \mathrm{C}$. The size of the effect is 3.54 and $4.4 \mathrm{~J} / \mathrm{g}$ for these two alloys, and by applying the method outlined in [22], we obtain virtually identical values of $\Delta H_{\mathrm{A}-\mathrm{B}}$ for the two alloys: $\Delta H_{\mathrm{A}-\mathrm{B}}=28.6 \mathrm{~kJ} / \mathrm{mol}$. We adopt the latter value throughout the present work, and the resulting (metastable) solvus for co-clusters in ternary Al-Mg-Si alloys is plotted in Fig. 2. In Fig. 2b, the solvus is compared with solvi for the $\beta\left(\mathrm{Mg}_{2} \mathrm{Si}\right), \beta^{\prime}-$ $\mathrm{Mg}_{18} \mathrm{Si}_{10}$ and $\beta^{\prime \prime}-\mathrm{Mg}_{5} \mathrm{Si}_{6}$ phases (data from $[24,25]$ ).

The obtained $\Delta H_{\mathrm{A}-\mathrm{B}}$ equates to $14.3 \mathrm{~kJ}$ per mol atoms in the precipitates, which, as expected for a metastable structure, is lower than the measured enthalpy of formation of $\beta\left(\mathrm{Mg}_{2} \mathrm{Si}\right)$ phase (26.3 kJ per mol from [26] and $21.1 \mathrm{~kJ}$ per mol from [25]) and the enthalpy of formation of $\beta\left(\mathrm{Mg}_{2} \mathrm{Si}\right)$ phase determined using first-principles total energies modelling $(17.7 \mathrm{~kJ}$ per mol from [25]).

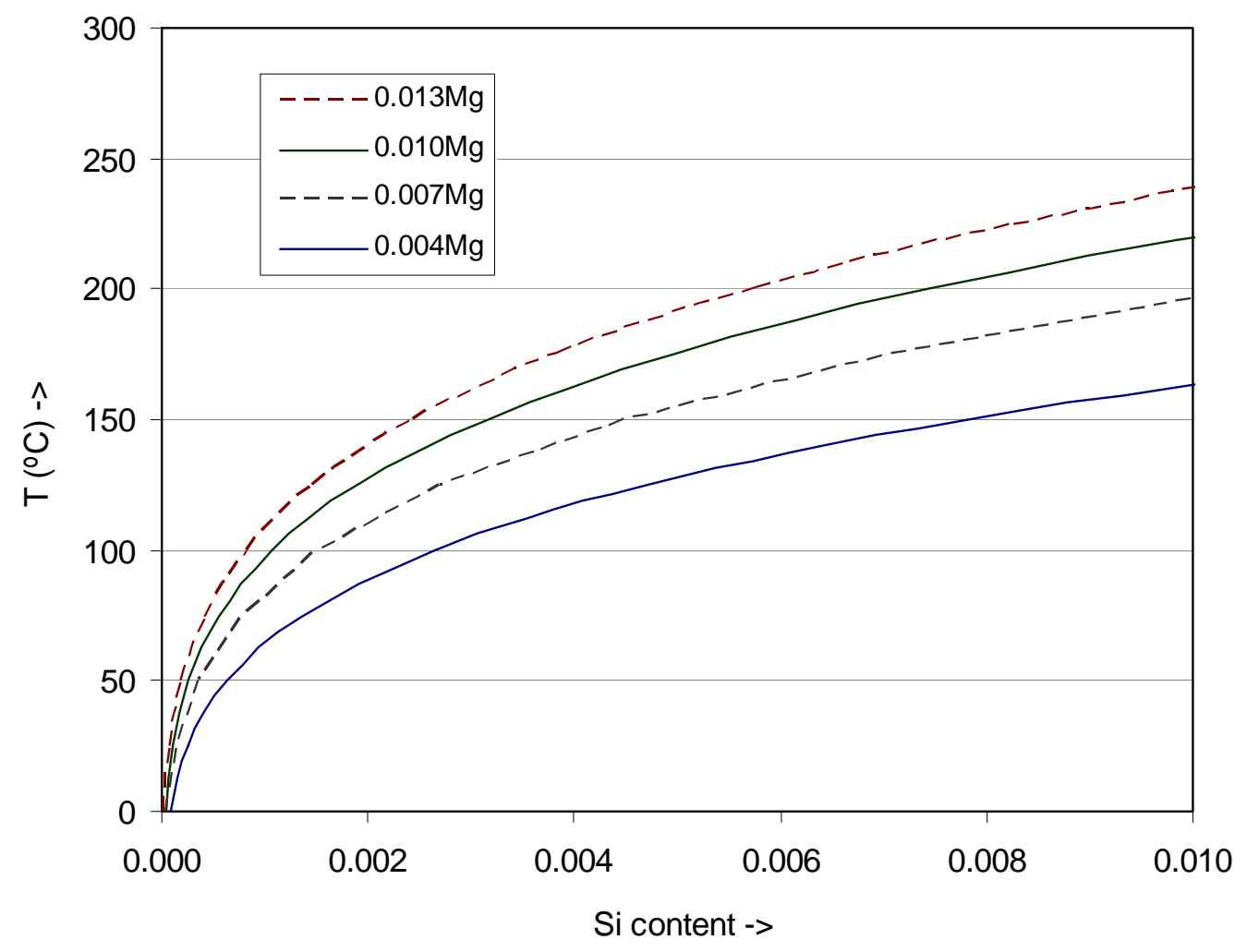




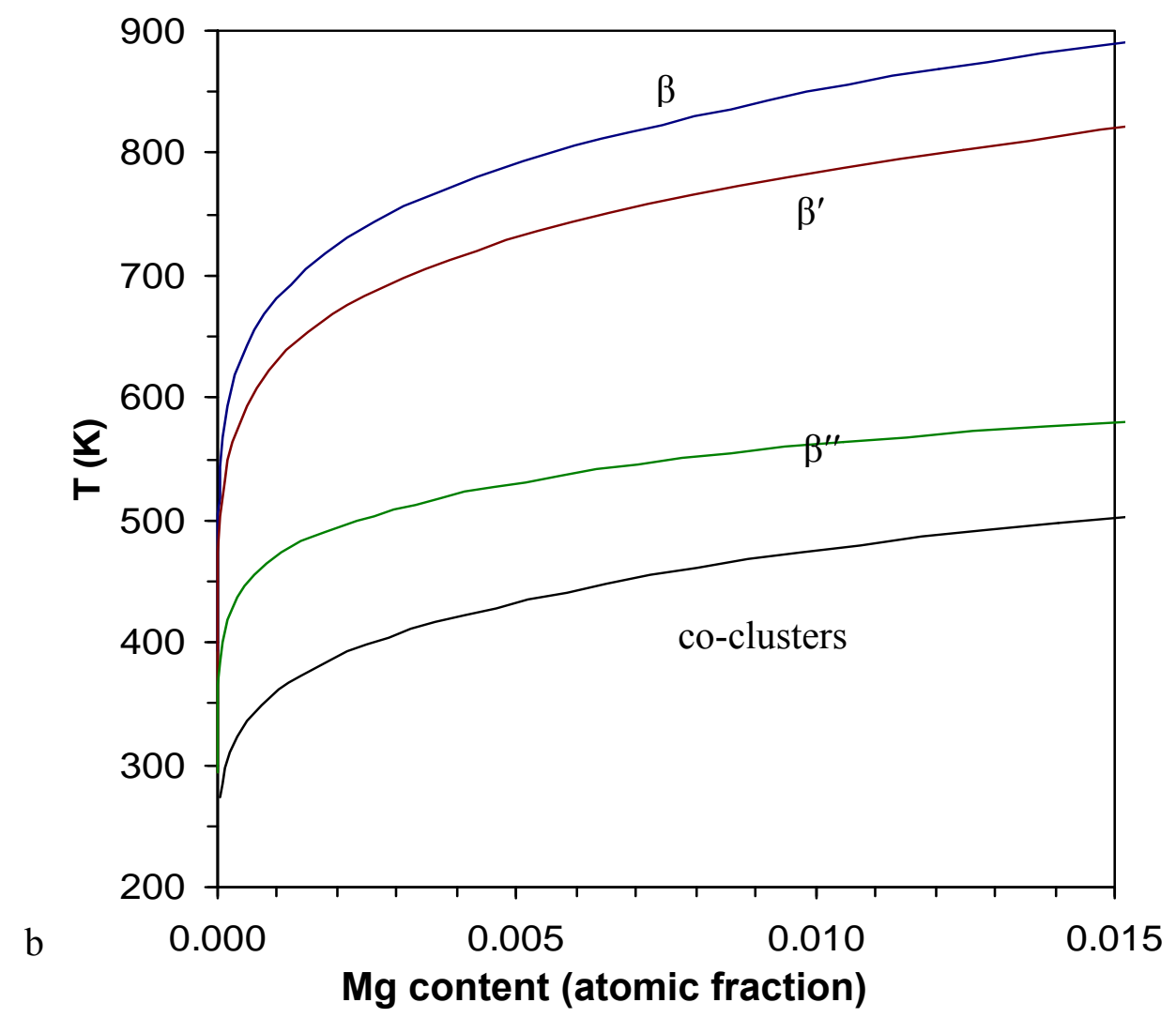

Fig. 2 Predictions of solvus of co-clusters in Al-Mg-Si based alloys from the model outlined in Section 2.1. a) As a function of Si content for various $\mathrm{Mg}$ contents; b) in the isopleth of 0.76 at $\% \mathrm{Si}$, including comparison with the solvus for $\beta$ (from the COST database [24]), $\beta^{\prime \prime}$ and $\beta^{\prime}$ (from first-principles total energies modelling in [25]). Solute contents (atomic fraction) reflect the amount dissolved in the Al-rich fcc phase following solution treatment and quenching.

\subsection{Strengthening due to co-clusters}

Clusters and co-clusters are shearable and hence the Orowan strengthening mechanism is not applicable. Two strengthening mechanisms related to obstacle shearing need to be considered: a) Order strengthening (including stacking fault strengthening), or configurational strengthening [27], and

b) Modulus hardening [28].

\section{Order strengthening}

For co-clusters, the strength of individual obstacles is low and the distance between obstacles on a shear plane is small. (Estimating the distance as $y_{\mathrm{A}}{ }^{-1 / 2} b$, with $y_{\mathrm{A}}$ the amounts of $\mathrm{A}$ in the co-clusters, provides a distance between co-clusters of about $10 b$ to $15 b$ for alloys considered 
here.) In these conditions, the classical approach based on bowing dislocations and their line tension, which leads to a volume fraction to the power of $1 / 2$ dependency (see e.g. [27]), is not valid. In the present work, we adopt the model for order strengthening from [22], which considers that the work done in deforming the lattice through the movement of dislocations hampered by (co-)clusters equals the change in energy related to the short range order per unit area on slip planes, i.e. $[22,29,30]$ :

$$
\Delta \tau_{s r o}=\frac{\gamma_{s r o}}{b}
$$

where $\gamma_{\text {sro }}$ is the change in energy per unit area on slip planes (which in most cases are $\{111\}$ planes) on the passing of one dislocation (a.k.a. the diffuse interphase boundary energy [29,31]). We will apply a simplified approach [22] that considers only nearest neighbour interactions for the co-cluster in Fig. 1a. This is done for the following reasons: i) we do not have sufficient accurate data to determine all the $\mathrm{k}^{\text {th }}$ interaction parameters, and ii) the simpler nearest neighbour method provides a more intuitively acceptable analysis, which is beneficial as it provides a more transparent model. (Issues related to this will be further considered in the Discussion.)

In the (M-rich) fcc lattice structure, each atom has 12 nearest neighbours and each atom adjacent to a slip plane will have 3 nearest neighbours on the other side of the $\{111\}$ slip plane. The area density of A-B nearest neighbour bonds crossing the slip plane is [22]:

$$
\rho_{A-B}\left(n_{d}=0\right)=\frac{\left(y_{A}+y_{B}\right)}{S_{111}}=\frac{4\left(y_{A}+y_{B}\right)}{\sqrt{3} b^{2}}
$$

where $S_{111}$ is the area on the 111 plane occupied by one atom, $y_{\mathrm{A}}$ and $y_{\mathrm{B}}$ are the respective amounts of $\mathrm{A}$ and $\mathrm{B}$ atoms in the co-clusters, and $x_{\mathrm{A}}$ and $x_{\mathrm{B}}$ are the respective amounts of $\mathrm{A}$ and $\mathrm{B}$ atoms in the M-rich phase. On the passing of one dislocation through the A-B cocluster, a part of the A-B bonds present before the passing will be destroyed and some will be retained. An illustration for 4-atom clusters is provided in Fig. 3; and an illustration for 2atom clusters is provided in [22].

For a single dislocation in an fcc lattice, 1/3 of the A-B nearest neighbour pairs will remain nearest neighbours. The passing through of a dislocation can also create $\mathrm{A}-\mathrm{B}$ nearest neighbour pairs, and their area density is given by $2 / 3 y_{\mathrm{A}} x_{\mathrm{B}}+2 / 3 y_{\mathrm{B}} x_{\mathrm{A}}+2 x_{\mathrm{A}} x_{\mathrm{B}}$ [22]. Thus the total area density of A-B nearest neighbour bonds crossing the slip plane after passage of one dislocation is [22]:

$$
\rho_{A-B}\left(n_{d}=1\right)=\frac{4}{\sqrt{3} b^{2}}\left[\frac{1}{3}\left(y_{A}+y_{B}\right)+\frac{2}{3} y_{A} x_{B}+\frac{2}{3} y_{B} x_{A}+2 x_{A} x_{B}\right]
$$



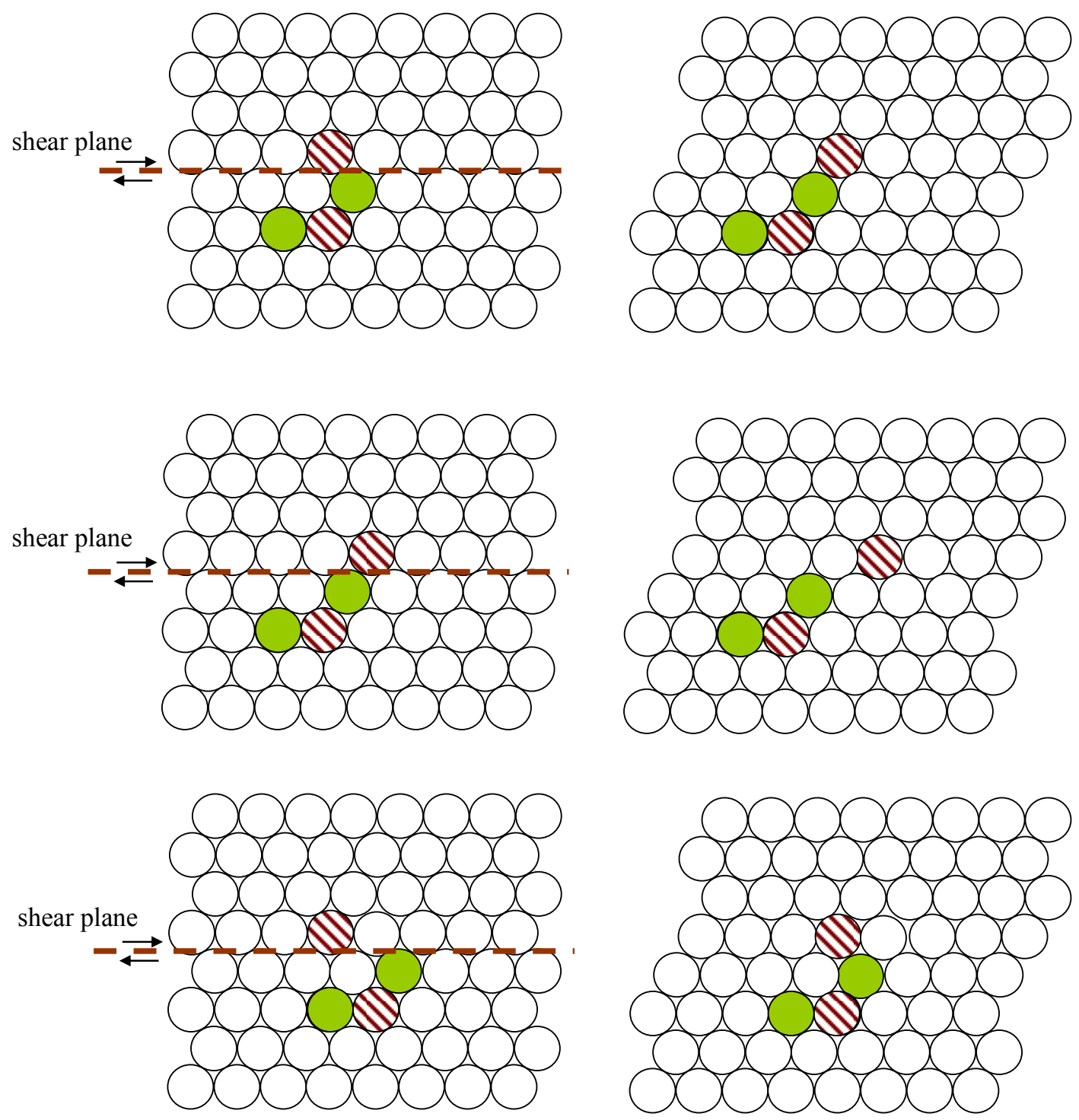

Fig. 3 Illustration of the cutting of a co-cluster by a moving dislocation for the case of a 4atom co-cluster lying in a 111 plane in an fcc lattice. Three cases are illustrated: cocluster remaining intact and no change in number of A-B bonds (top); one A-B bond being eliminated (middle); and the case where the passing of one dislocation creates an A-B bond (bottom).

The change in area density of A-B nearest neighbour bonds crossing the slip plane on the passing of one dislocation is 


$$
\begin{aligned}
& \rho_{A-B}\left(n_{d}=0\right)-\rho_{A-B}\left(n_{d}=1\right)=\frac{4}{\sqrt{3} b^{2}}\left[\frac{2}{3}\left(y_{A}+y_{B}\right)-\left(\frac{2}{3} y_{A} x_{B}+\frac{2}{3} y_{B} x_{A}+2 x_{A} x_{B}\right)\right] \\
& \cong \frac{4}{\sqrt{3} b^{2}} \frac{2}{3}\left(y_{A}+y_{B}\right)
\end{aligned}
$$

where the approximation is valid for dilute alloys. Passage of further dislocations will cause further changes in the area density of A-B nearest neighbour bonds crossing the slip plane. As the magnitude of these changes will decrease on the passing of each further dislocation, the first dislocation experiences the greatest resistance. Considering in approximation that the energy related to co-clusters is defined by the enthalpy of the nearest neighbour bond, $\Delta H_{\mathrm{A}-\mathrm{B}}$, we can approximate [22]:

$$
\begin{aligned}
& \Delta \tau_{s r o}=\frac{\gamma_{s r o}}{b}=\frac{\Delta H_{A-B}}{b}\left[\rho_{A-B}\left(n_{d}=0\right)-\rho_{A-B}\left(n_{d}=1\right)\right] \\
& =\frac{\Delta H_{A-B}}{b^{3}} \frac{4}{\sqrt{3}}\left[\frac{2}{3}\left(y_{A}+y_{B}\right)-\left(\frac{2}{3} y_{A} x_{B}+\frac{2}{3} y_{B} x_{A}+2 x_{A} x_{B}\right)\right]
\end{aligned}
$$

The latter equation is valid for any type of co-cluster, including 2-atom co-clusters and 4atom co-clusters provided that $\Delta H_{\mathrm{AB}-\mathrm{AB}}<<\Delta H_{\mathrm{A}-\mathrm{B}}$.

Modulus hardening

Nembach [28] analysed modulus hardening by a calculation of the interaction forces of screw and edge dislocations as they pass through the area (precipitate) with differing modulus. This approach is based on Friedel's approximation:

$$
\Delta \tau=1.4 \frac{F_{o}^{3 / 2} f^{1 / 2}}{r b(2 \pi S)^{1 / 2}}
$$

Nembach's analysis [28] shows that the critical shear stress due to modulus hardening can be represented as:

$$
\Delta \tau_{m}=1.4 \alpha_{1}^{3 / 2} \Delta \mu^{3 / 2} f_{c l}{ }^{1 / 2} b\left(\frac{r_{c l}}{b}\right)^{3 \alpha_{2} / 2-1}(2 \pi T)^{-1 / 2}
$$

where $T$ is the dislocation line tension, $f_{\mathrm{cl}}$ is the volume fraction of clusters, $r_{\mathrm{cl}}$ is the equivalent radius of the clusters, $\alpha_{1}$ and $\alpha_{2}$ are parameters that are obtained from the dislocation-precipitate interaction models, and $\Delta \mu$ is the difference in shear modulus between clusters, $\mu_{c l}$, and the surrounding fcc phase. As different dislocation core models predict somewhat different interaction forces between dislocations and precipitates [28], some uncertainty in $\Delta \tau_{\mathrm{m}}$ results. Averaged values are obtained for $\alpha_{1}=0.096$ and $\alpha_{2}=0.76$, respectively. No data is available on $\mu_{c l}$ for Mg-Si co-clusters. As Mg-Si co-clusters in many respects seem very similar to $\mathrm{Cu}-\mathrm{Mg}$ co-clusters (including a similar $\Delta H_{\mathrm{cl}}$ ) we will take $\mu_{c l}$ from earlier work on clusters in $\mathrm{Al}-\mathrm{Cu}-\mathrm{Mg}$ alloys [22]. 


\subsection{Other strengthening mechanisms}

The yield strength of an alloy that contains co-clusters is dominated by the contribution due to the co-clusters, with further minor contributions due to grain boundaries, dislocations, solute in the Al-rich phase and some stress transfer to intermetallic particles [22,32]. A general approximation of the superposition of strengthening mechanisms is [33]:

$$
\begin{aligned}
\sigma_{y} & =\sigma_{g b}+M\left(\tau_{o}+\tau_{s o l}+\tau_{d}+\tau_{c l}+\tau_{o r}\right) \\
& =\sigma_{g b}+M\left(\tau_{o}+\tau_{s o l}+\tau_{d}+\left(\Delta \tau_{s r o}+\Delta \tau_{m}\right)+\tau_{o r}\right)
\end{aligned}
$$

where $\sigma_{\mathrm{gb}}$ is the yield strength contribution due to grain boundaries, $\tau_{\mathrm{d}}$ is the critical resolved shear stress increment due to stored dislocations (introduced by plastic deformation), $\tau_{\text {sol }}$ is due to dissolved elements, $\tau_{\text {or }}$ is the strengthening due to non-shearable particles by the Orowan mechanism, $\tau_{\mathrm{cl}}$ is the strengthening due to shearable clusters, $\tau_{\mathrm{o}}$ is the friction stress and $M$ is the Taylor factor. In this case, the contributions due to $\sigma_{\mathrm{gb}}, \tau_{\mathrm{sol}}, \tau_{\mathrm{or}}$ and $\tau_{\mathrm{o}}$ are all so small that they have a relatively limited effect on the model predictions. Using the Hall-Petch relation with a Hall-Petch constant taken from [34], the $\sigma_{\mathrm{gb}}$ value is only about $4 \mathrm{MPa}$. (Where specific data on grain size is lacking, it is taken as $50 \mu \mathrm{m}$, a typical value for extruded and rolled alloys with Mn [35].) The alloys considered in this work are all solution treated and hence the dislocation densities are low. As the alloys contain up to about 3 vol\% intermetallic particles, some dislocations can be generated due to the misfit caused by differences in the thermal expansion coefficients. To address this, we add a prediction of dislocation density generated by this to the model, following the work by Chawla [36]. The contribution to the strength is small, up to $6 \mathrm{MPa}$ for 6xxx alloys with the higher Mn and Fe contents (high $\mathrm{Mn}$ and $\mathrm{Fe} 6 \mathrm{xxx}$ alloys typically contain over $0.1 \mathrm{at} \%$ of each element). In addition, we also add strengthening due to stress transfer to the intermetallic particles by applying the treatment in [37,38]. This contribution is also low, with typically about $1 \%$ increase in yield strength for alloys with the higher $\mathrm{Mn}+\mathrm{Fe}$ content.

The parameters applied in the model are all either directly taken or derived from the existing literature, and are summarised in Table 1. (Some issues related to model parameters are discussed in Section 5.)

In Fig. 4, model predictions are presented for the strength of 6xxx alloys that are quenched and aged at room temperature to the completion of co-cluster formation. In this case, the $\mathrm{Mn}$ $+\mathrm{Fe}$ content is $0.3 \mathrm{wt} \%$, which is typical for some of the common commercial $6 \mathrm{xxx}$ alloys. Fig. 5 shows model predictions of the various contributions to the critical resolved shear stress. 
Table 1. Parameters of the model.

\begin{tabular}{|c|c|c|}
\hline Parameter & Value & Source, reference \\
\hline Burgers vector length, $b$ & $0.286 \mathrm{~nm}$ & \\
\hline Gas constant, $R$ & $8.31 \mathrm{~J} /(\mathrm{mol} . \mathrm{K})$ & \\
\hline$\Delta H_{\mathrm{Mg}-\mathrm{Si}}$ & $28.6 \mathrm{~kJ} / \mathrm{mol}$ & This work \\
\hline $\begin{array}{l}\text { Enthalpy due to } \mathrm{Si} \text { cluster formation per mol } \mathrm{Si} \text { in } \\
\text { clusters } \Delta H_{\mathrm{Si}-\mathrm{Si}}\end{array}$ & $\sim 10 \mathrm{~kJ} / \mathrm{mol}$ & $\begin{array}{l}\text { This work, } \\
\text { Section } 6.2\end{array}$ \\
\hline$M$ & $2.73 \pm 0.1$ (L direction) & See Section 5 \\
\hline$\tau_{0}$ & $5 \mathrm{MPa}$ & See Section 5 \\
\hline Shear modulus differential matrix-clusters, $\Delta \mu_{c l}$ & $4 \mathrm{GPa}$ & {$[22]$} \\
\hline Solution CRSS hardening factor $\mathrm{Si}, k_{\mathrm{Si}}$ & $800 \mathrm{MPa} / \mathrm{at} \% \mathrm{Si}$ & from data in [77] \\
\hline Solution CRSS hardening factor $\mathrm{Mg}, k_{\mathrm{Mg}}$ & $590 \mathrm{MPa} / \mathrm{at} \% \mathrm{Mg}$ & {$[39,40]$} \\
\hline Solution CRSS hardening factor $\mathrm{Cu}, k_{\mathrm{Cu}}$ & $k_{\mathrm{Cu}} \approx k_{\mathrm{Mg}}$ & {$[41]$} \\
\hline Average thermal expansion coefficient $\mathrm{Al}, \alpha_{\mathrm{Al}}$ & $2.410^{-5} \mathrm{~K}^{-1}$ & {$[42]$} \\
\hline $\begin{array}{l}\text { Average thermal expansion coefficient of } \\
\text { undissolved intermetallic particles, } \alpha_{\mathrm{AlFeMnSi}}\end{array}$ & $\sim 1.710^{-5} \mathrm{~K}^{-1}$ & $\begin{array}{l}\text { Estimated from } \\
\text { data in [43] }\end{array}$ \\
\hline $\begin{array}{l}\text { Effective temperature drop over which misfit } \\
\text { dislocations are generated, } \Delta T\end{array}$ & $\sim 400 \mathrm{~K}$ & \\
\hline Young's modulus of AlFeMnSi intermetallics & $175 \mathrm{GPa}$ & {$[44]$} \\
\hline Hall-Petch coefficient & $25 \mathrm{MPa} . \mu \mathrm{m}^{1 / 2}$ & {$[34]$} \\
\hline
\end{tabular}

\section{$3 \quad$ Experimental}

The chemical compositions of the alloys investigated in this work are given in Table 2. All alloys were DC cast and subsequently homogenised and hot and cold rolled. The Al- $0.5 \mathrm{Mg}$ $1 \mathrm{Si}-0.1 \mathrm{Cu}$ alloy was solution treated for $0.5 \mathrm{~h}$ in a salt bath at $550{ }^{\circ} \mathrm{C}$, quenched in room temperature water and then naturally aged only (designated as T4). Atom probe experiments were carried out after natural ageing times of 1.1, 3, 24.5, 165 and 720 hours. Tensile testing was carried out on samples with a cross-sectional area of $5 \mathrm{~mm}^{2}$ and a gauge length of $20 \mathrm{~mm}$ using an Instron 4505 tensile machine at an extension rate of $1.0 \mathrm{~mm} / \mathrm{min}$. Up to three tests were performed for each condition. The Al-1Mg-0.2Si and $\mathrm{Al}-1 \mathrm{Mg}-0.1 \mathrm{Si}-0.1 \mathrm{Cu}$ alloys were solution treated at $500^{\circ} \mathrm{C}$ for $0.5 \mathrm{~h}$ and subsequently quenched in water. The tensile testing on these two alloys was performed according to the ASTM-E8M standard using an 8800 series Instron machine at a constant strain rate of $0.001 \mathrm{~s}^{-1}$. For each condition usually two tests were performed.

3DAP analysis was performed on the Al-0.5Mg-1Si-0.1Cu alloy, using an Oxford nanoScience energy-compensated three-dimensional atom probe field ion microscope under 
ultrahigh vacuum conditions $\left(<10^{-10}\right.$ mbar) with a pulse fraction of $20 \%$, at a specimen temperature of $25 \mathrm{~K}$, and with a detector efficiency of $45 \%$. Samples sized $0.5 \times 0.5 \times 10 \mathrm{~mm}^{3}$ were wire cut from the cold-rolled sheet with the needle axis aligned along the rolling direction. These samples were wrapped in aluminium foil for solution treatment in a salt bath. Sharp tips were subsequently prepared with a standard two-stage electro-polishing technique using a $33 \%$ nitric acid- $-67 \%$ methanol solution for stage one and a $2 \%$ perchloric acid- $-98 \%$ butoxyethanol solution for stage two.

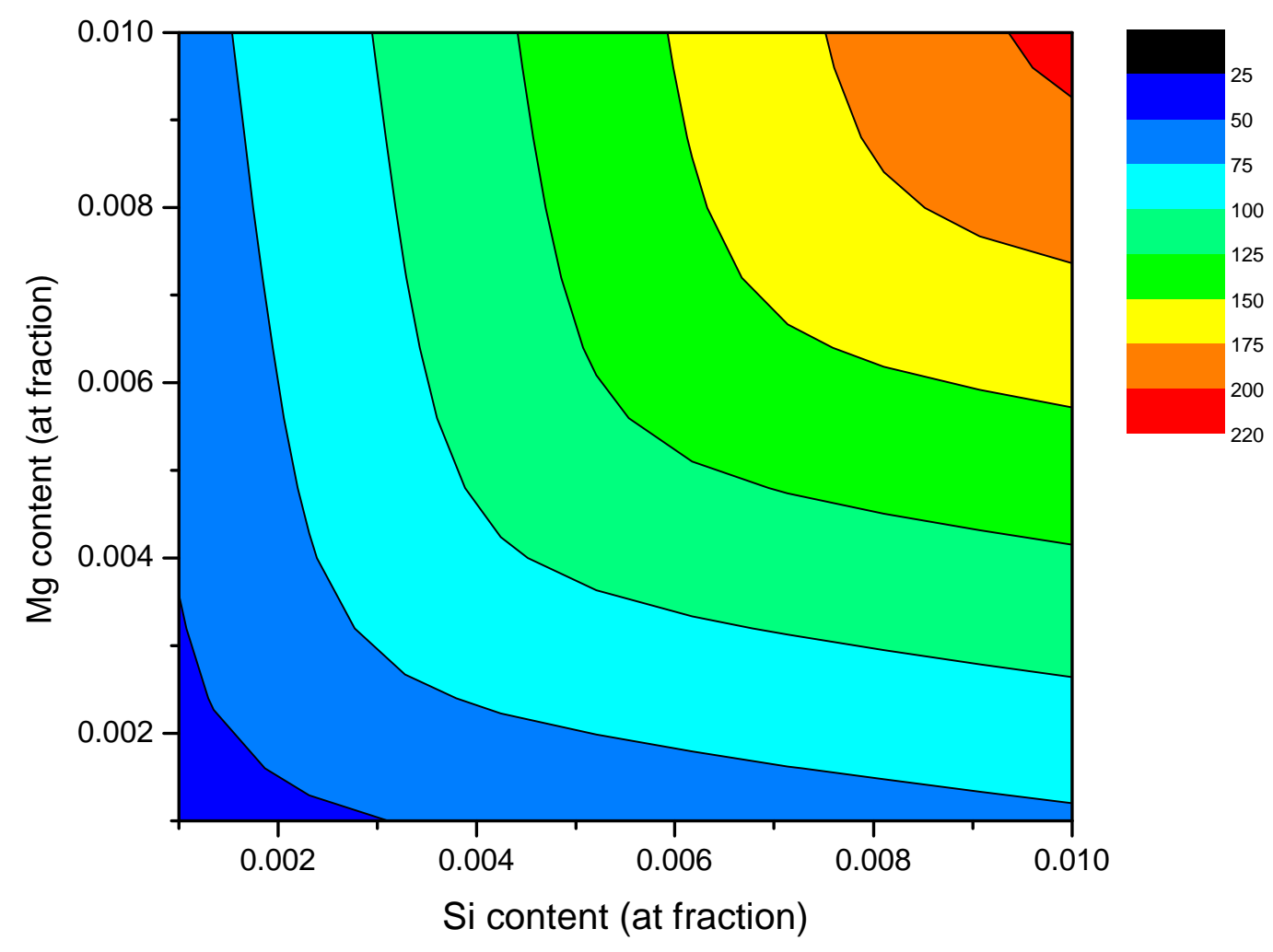

Fig. 4 Model predictions of T4 yield strength from the present model for Al-Mg-Si-0.1Fe$0.2 \mathrm{Mn}(\mathrm{at} \%)$ alloys, after natural ageing for $>1$ week.

Table 2. Chemical compositions of the alloys studied (at \%).

\begin{tabular}{|l|l|l|l|l|l|l|l|l|l|}
\hline & & Si & Mg & Cu & Fe & Mn & Cr & Zn & Ti \\
\hline Alloy 1 & Al-0.5Mg-1Si-0.1Cu & 1.03 & 0.54 & 0.12 & 0.06 & 0.03 & 0.04 & 0.08 & 0.01 \\
\hline Alloy 2 & Al-1Mg-0.2Si & 0.15 & 1.09 & $<0.01$ & 0.11 & 0.12 & $<0.001$ & $<0.002$ & 0.01 \\
\hline Alloy 3 & Al-1Mg-0.1Si-0.1Cu & 0.14 & 1.08 & 0.08 & 0.10 & 0.13 & $<0.001$ & $<0.002$ & 0.01 \\
\hline
\end{tabular}



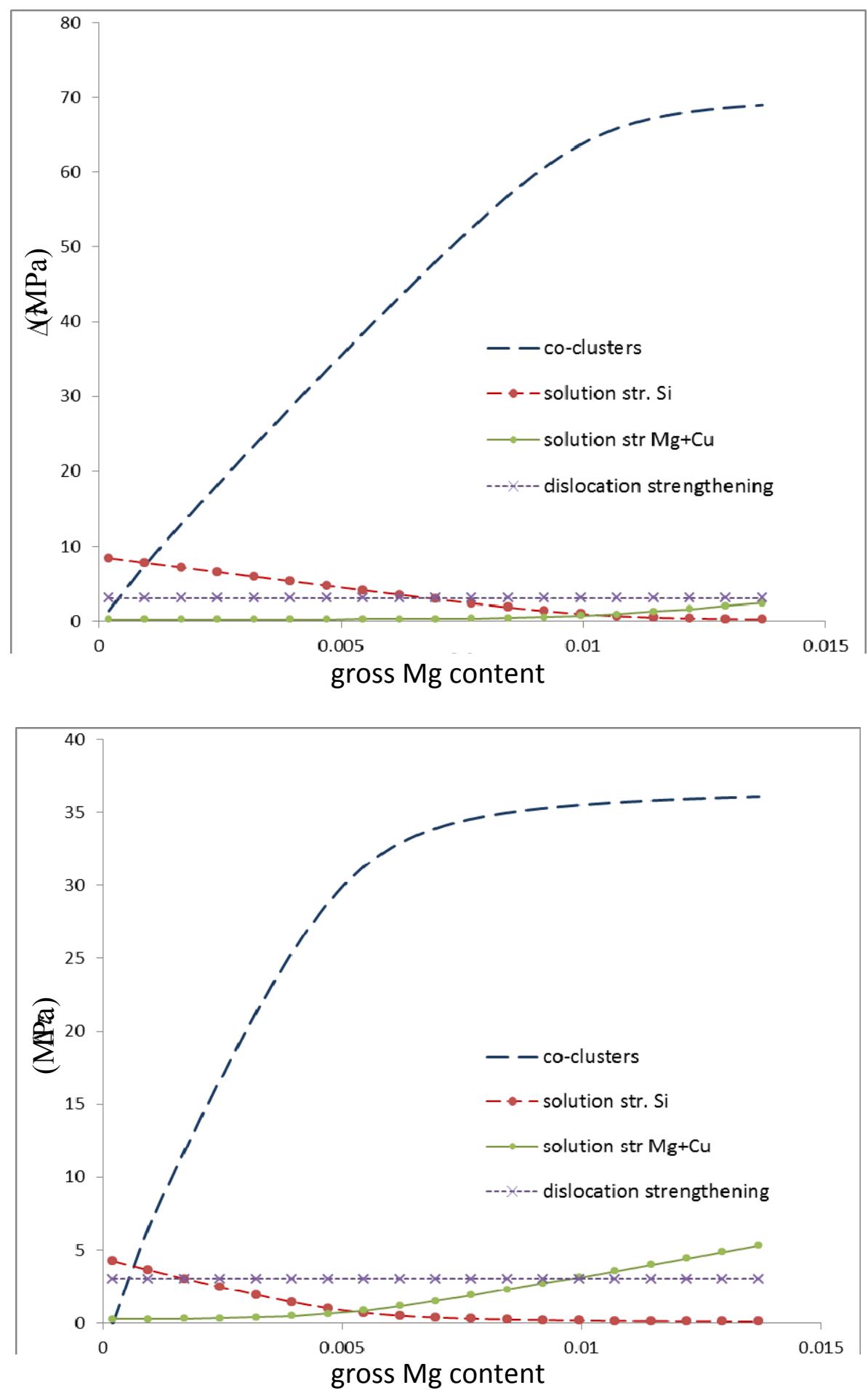

Fig. 5 Model predictions of contributions to the critical resolved shear stress in the T4 condition after natural ageing for $>1$ week, from the present model for Al-Mg-Si$0.1 \mathrm{Fe}-0.2 \mathrm{Mn}$ (at $\%$ ) alloys with (a) $1 \mathrm{at} \% \mathrm{Si}$; (b) $0.5 \mathrm{at} \% \mathrm{Si}$.

3DAP data analyses were carried out using both PoSAP 1.76.1 (2008) and IVAS ${ }^{\mathrm{TM}}$ 3.4.1 (2009) software. Various values were tested for the commonly used particle analysis 
parameters: maximum distance between solute atoms $\left(D_{\max }\right)$, surround distance $(L)$, erosion distance $(S)$ and the minimum number of detected solute atoms comprising a cluster $\left(\mathrm{N}_{\min }\right)$. The IVAS integrated cluster finding and analysis tool was used to determine optimum values for $D_{\max }$ and $\mathrm{N}_{\min }$ by maximising the ratio of actual to random signals based on the nearest neighbour, cluster size and cluster count distribution plots of actual and randomised data. In the end, it was decided that the cluster analysis results should be compared across different datasets with $D_{\max }, L$ and $S$ all set to $0.5 \mathrm{~nm}$. After considering a range of $\mathrm{N}_{\min }$ values, it was decided that the choice of $\mathrm{N}_{\text {min }}=5$ was large enough to minimise errors due to random clustering effects, and small enough to resolve a significant amount of small clusters occurring in the T4 condition. For some aspects of the work, $\mathrm{N}_{\min }=2$ was used in order to study the behaviour of the smallest clusters with only two to four solute atoms. When reporting Mg:Si ratios in clusters we will correct these for preferential evaporation effect by multiplication by the ratio of measured to actual $\mathrm{Mg}$ :Si content of the alloy.

To study undissolved intermetallic particles in the 3 alloys, samples for analysis by a field emission gun scanning electron microscope (FEG-SEM) were cut from rolled solution treated sheets. They were mounted, ground and polished using standard procedures. The FEG-SEM was equipped with an energy dispersive spectrometer (EDS) for compositional analysis. In addition, thermodynamic modelling using Thermocalc with the COST database was employed to provide additional information on the probable compositions of intermetallic phases and dissolution of $\mathrm{Mg}_{2} \mathrm{Si}$ during solution treatment.

\section{$4 \quad$ Experimental Results and Analysis}

It is important to point out upfront that the detection of small clusters using 3DAP has limitations, which are primarily caused by the detection efficiency typically being around $50 \%$. For samples with very small clusters it is common to select a value of $\mathrm{N}_{\text {min }}$ which gives a compromise between excessive detection of clusters (excessive false positives) and low volume fractions of clusters. We first provide data for $\mathrm{N}_{\min }=5$. Fig. 6 shows a 3D representation of the clusters detected in the Al-0.5Mg-1Si- $0.1 \mathrm{Cu}$ alloy for natural ageing times of 1.1, 24.5 and $720 \mathrm{~h}$. (3DAP data for ageing times of 3 and $165 \mathrm{~h}$ gave results in line with those presented here.) The figure reveals the presence of clusters, which are nearly exclusively Mg-Si co-clusters; in all analysed samples, $\mathrm{Si}$ and $\mathrm{Mg}$ together account for 94 to $98 \%$ of all solute atoms present in the clusters.

In Fig. 7, the evolution of cluster volume fraction during ageing at room temperature is plotted for the Al-0.5Mg-1 Si-0.1Cu alloy. The Mg:Si ratio in the clusters shows no clear trend during natural ageing and equals $0.86 \pm 0.17$. (Note that due to taking $\mathrm{N}_{\min }=5$ and the limitations of 3DAP (detection efficiency), the volume fraction of clusters is expected to be underestimated and the average number of atoms per cluster will be overestimated.) 
(a) $1.1 \mathrm{~h}$

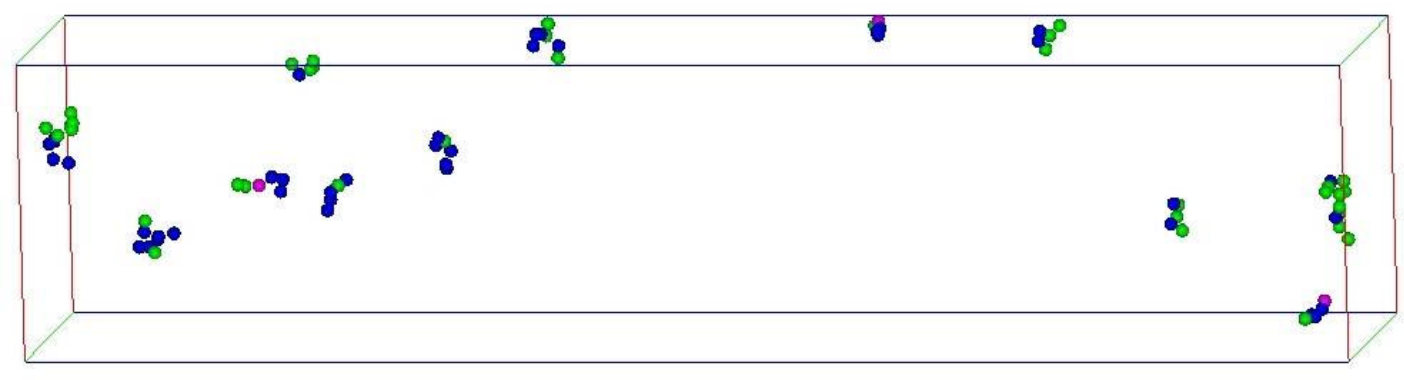

(b) $24.5 \mathrm{~h}$

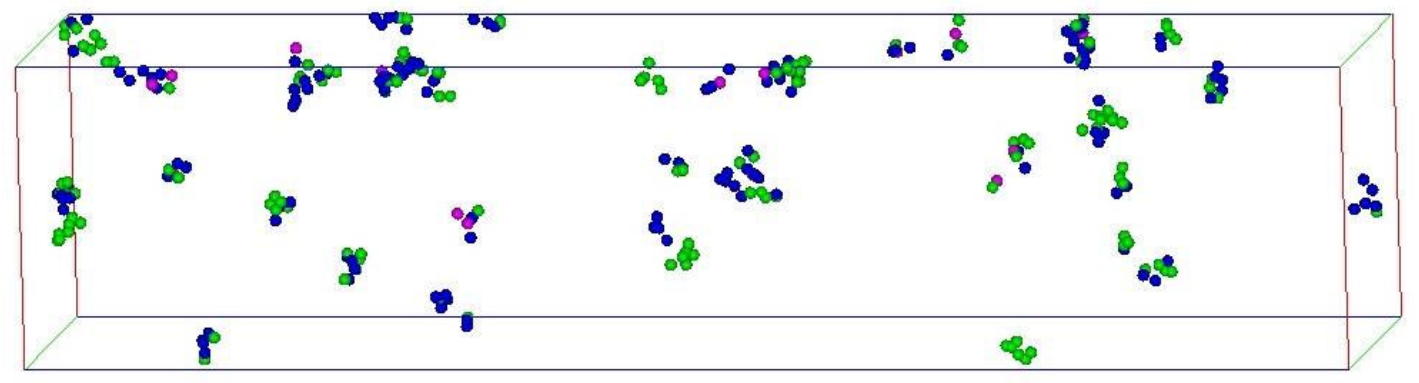

(c) $720 \mathrm{~h}$

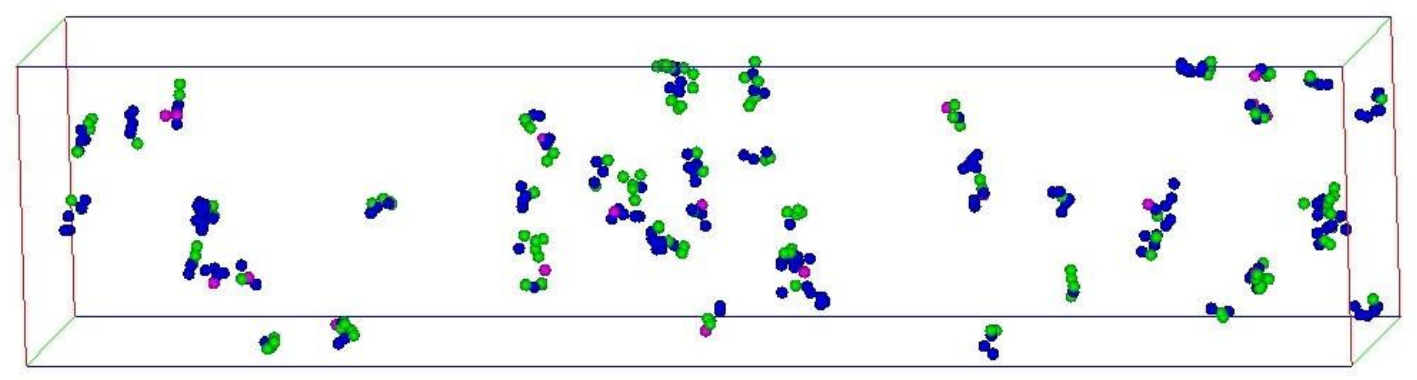

Fig. 6 3DAP atom maps showing all clusters identified in a volume of 10x10x44 nm 3 for room temperature ageing times of 1.1, 24.5 and $720 \mathrm{~h}$. Intermediate natural ageing times of 3 and $165 \mathrm{~h}$ (not presented here) provide results in line with these. $\mathrm{Mg}=$ green, $\mathrm{Si}=$ blue and $\mathrm{Cu}=$ pink.

To further analyse the $\mathrm{Mg}$ :Si ratio of the clusters, we plotted the $\mathrm{Mg}$ :( $\mathrm{Mg}+\mathrm{Si})$ ratio of clusters as a function of the total number of $\mathrm{Mg}$ and $\mathrm{Si}$ atoms detected in the clusters using $\mathrm{N}_{\min }=2$. This analysis showed that for small clusters the ratio is consistent with the overall $\mathrm{Mg}$ and $\mathrm{Si}$ content of the alloy, but for increasing size, the $\mathrm{Mg}$ :Si ratio increases to 1 . Thus the measured $\mathrm{Mg}: \mathrm{Si}$ ratio for the larger clusters, for which the determination of $\mathrm{Mg}: \mathrm{Si}$ ratio is most accurate, is consistent with the model. For very small clusters, the Si content of the clusters appears to be somewhat higher than the model assumption of a $\mathrm{Mg}$ :Si ratio of 1 . 
In Fig. 7, the hardness and yield strength evolution for the Al-0.5Mg-1Si-0.1Cu alloy during ageing at room temperature are also plotted. Both the hardness and the yield strength appear to reach a plateau after about $100-200 \mathrm{~h}$ of natural ageing.

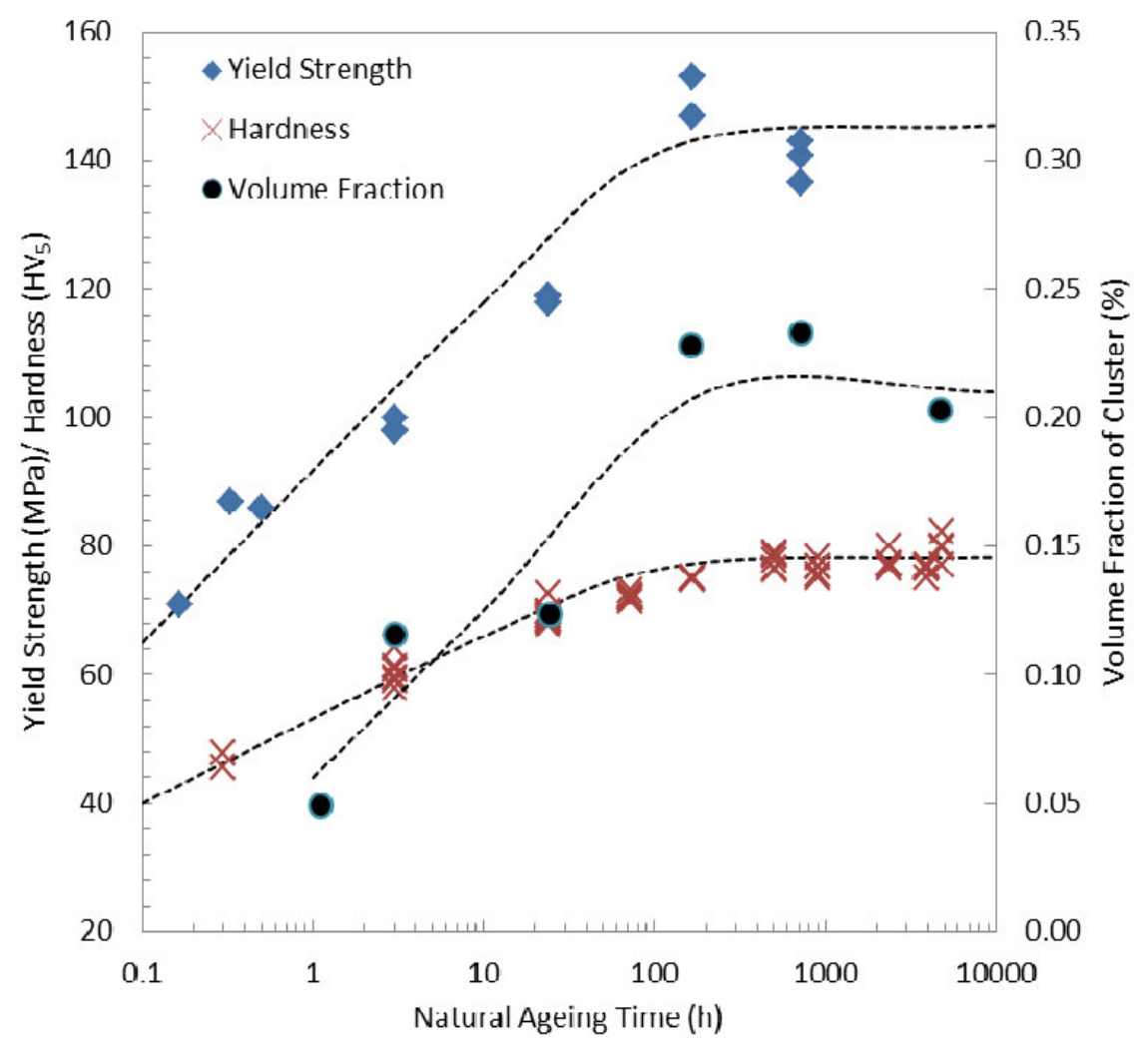

Fig. 7 Hardness, yield strength and cluster volume fraction evolution for the Al-0.5Mg-1Si$0.1 \mathrm{Cu}$ alloy during ageing at room temperature. The volume fraction of clusters was determined using $\mathrm{N}_{\min }=5, \mathrm{D}=\mathrm{L}=\mathrm{S}=0.5 \mathrm{~nm}$. Dotted lines represent a guide to the eye only.

\section{Strength and hardness model predictions based on the co-cluster model}

To verify the model we will compare yield strength predictions with data for a range of solution treated and subsequently aged Al-Mg-Si based alloys. We included all data on commercial 6xxx-T4 available from databooks / databases [45,46,47,48,49,50,51,52] with $\mathrm{Cu}$ content lower than $0.7 \mathrm{wt} \%$ and all data on room temperature aged $6 \mathrm{xxx}$ alloys from the last 10 years published in papers $[18,53,54,55,56,57]$. We omitted data for which quoted compositions were inconsistent with specifications (e.g. data on 6082 in [58]), where yield strength data was inconsistent between different sources (6082 T4) and alloys for which full solutionising of $\mathrm{Mg}_{2} \mathrm{Si}$ is not achieved in regular T4 tempers (e.g. 6066). In addition, data on 
the as-quenched hardness of one 6xxx alloy (from [50]) and $\mathrm{Mg}$-free $\mathrm{Al}-0.2 \mathrm{Fe}-0.2 \mathrm{Si}$ is included.

Model parameters are listed in Table 2; most values were taken from [22], and all parameters are taken from existing literature. The values of $M$ and $\tau_{\mathrm{o}}$ required some analysis. For texturefree fcc metals, $M$ obtained from self-consistent models is 2.6 ([59] see also [60,61]. However, the present data is on extruded and rolled alloys which do have a strong texture, and we will take account of that. For rolled and extruded alloys, generally the yield strength will be lowest in a direction at a $45^{\circ}$ angle from the longitudinal (L) direction (see [62] for Al-Zn$\mathrm{Mg}$ extrusions, [63] for Al-Cu based sheet, [64] for commercial purity sheet, [65] for a recovery annealed aluminium alloy), and the $\mathrm{L}$ direction has the highest yield strength. The increment in $M$ in the $\mathrm{L}$ direction compared to the texture free case is on average $5 \%$ (from data in $[50,61,63,64])$. As a detailed study of texture and $M$ factor is beyond the scope of the present work, we will thus take $M=1.05 \times 2.6=2.73$ as being the best approximation for yield strength data in the $\mathrm{L}$ direction. With all the above strengthening contributions accounted for, $M \tau_{\mathrm{o}}$ represents the yield strength of near pure Al with very small concentration of as yet unaccounted for elements $(\mathrm{Zn}, \mathrm{Ti}, \mathrm{Cr})$, and hence should be similar to the yield strength of coarse grained Al of purity $\sim 99.8 \%$, which provides $\tau_{\mathrm{o}}=6 \mathrm{MPa}$ [66]. (Predictions for solution strengthening using averaged solution strengthening factors from predictions in [41] with typical impurity contents in 6xxx alloys provide similar prediction for $\tau_{\mathrm{o}}$.)

Solution strengthening by $\mathrm{Si}$ is based on strength data of an Al-1at $\% \mathrm{Si}$ alloy in which cluster formation was suppressed by quenching in brine, storage in liquid nitrogen and testing at $76^{\circ} \mathrm{C}$ [67]. This provides a CRSS solution strengthening factor of $800 \mathrm{MPa}$. Solution strengthening by $\mathrm{Cu}$ is taken from [68], and solutions strengthening by $\mathrm{Mg}$ is taken from $[69,70]$. (In the present alloys, solution strengthening is relatively minor, providing on average only $7 \%$ of the total yield strength.)

The results, presented in Fig. 8 and Table 3, show a very good correspondence: the typical accuracy (root mean square error) is $6 \mathrm{MPa}$. This limited level of deviations is thought to be mostly due to small uncertainties not related to the present strength model, including uncertainties in $M$ and in alloy composition. (A 0.1 at $\%$ change in $\mathrm{Mg}$ content on average causes a $6 \mathrm{MPa}$ change in predicted $\sigma_{\mathrm{y}}$ ).

Table 3 clearly illustrates that the strengthening due to co-clusters is dominated by the short range order mechanism, with the modulus strengthening mechanism accounting for less than $7 \%$ of the hardening due to co-clusters.

Table 3. Predicted and measured yield strengths (PS) of a range of commercial and experimental alloys. $\mathrm{ST}=$ solution treated, $\mathrm{T} 4=$ solution treated and naturally aged, $\mathrm{O}=$ annealed [47]. * converted from hardness data 


\begin{tabular}{|c|c|c|c|c|c|c|c|}
\hline Alloy & Treatment & $\begin{array}{l}\text { Model Predic } \\
\text { Co-cluster } \\
\text { content } \\
\text { at } \%\end{array}$ & $\begin{array}{l}\text { Oons } \\
\Delta \tau_{\mathrm{SRO}} \\
\mathrm{MPa}\end{array}$ & $\begin{array}{l}\Delta \tau_{\text {mod }} \\
\mathrm{MPa}\end{array}$ & $\begin{array}{c}\text { Predicted } \\
\text { PS } \\
\mathrm{MPa}\end{array}$ & $\begin{array}{l}\text { Measured } \\
\qquad \begin{array}{c}\mathrm{PS} \\
\mathrm{MPa}\end{array}\end{array}$ & Reference / source \\
\hline AA1060 & $\mathrm{O}$ & 0 & 0.0 & 0.0 & 30 & 30 & Kaufman [49] \\
\hline AA5457 & $\mathrm{T} 4$ & 0.06 & 17.5 & 1.3 & 54 & 50 & Davis [47], Kaufman [49] \\
\hline AA6010 & $\mathrm{T} 4$ & 1.52 & 89.4 & 6.7 & 183 & $186^{1}$ & Chandler [50] \\
\hline AA6011 & $\mathrm{T} 4$ & 0.97 & 71.5 & 5.4 & 139 & 145 & Quaino [53] \\
\hline AA6016 & $\mathrm{T} 4$ & 0.87 & 67.7 & 5.1 & 132 & 125 & Haga et al [54] \\
\hline AA6022 & $\mathrm{T} 4$ & 0.99 & 72.3 & 5.4 & 140 & 131 & Yan-Li [56] \\
\hline $\mathrm{AA} 6022+\mathrm{Cu}$ & $\mathrm{T} 4$ & 0.94 & 70.6 & 5.3 & 137 & 135 & Yan-Li [56] \\
\hline AA6061 & $\mathrm{T} 4$ & 0.99 & 72.4 & 5.4 & 140 & 145 & Davis [47], Kaufman [49] \\
\hline AA6061 & ST & 0.0 & 0.0 & 0.0 & 50 & 55 & Chandler [50] \\
\hline AA6063 & $\mathrm{T} 4$ & 0.74 & 62.3 & 4.7 & 108 & 101 & Marchive [52] \\
\hline AA6351 & T4 & 1.18 & 78.8 & 5.9 & 155 & 150 & [46], Davis [47], Kaufman [49] \\
\hline Al-0.5Mg-1.0Si & T4 & 1.04 & 74.0 & 5.5 & 143 & 148 & This work \\
\hline Al-0.6Mg-1.2Si & T4 & 1.38 & 85.3 & 6.4 & 172 & $180^{*}$ & Chang et al [55] \\
\hline Al-0.8Mg-0.4Si & T4 & 0.80 & 65.1 & 4.9 & 110 & 118 & {$[57]$} \\
\hline $\mathrm{Al}-1 \mathrm{Mg}-0.2 \mathrm{Si}$ & ST & 0 & 0.0 & 0.0 & 44 & 49 & This work \\
\hline Al-1Mg-0.2Si-0.2Cu & ST & 0 & 0.0 & 0.0 & 45 & 51 & This work \\
\hline
\end{tabular}

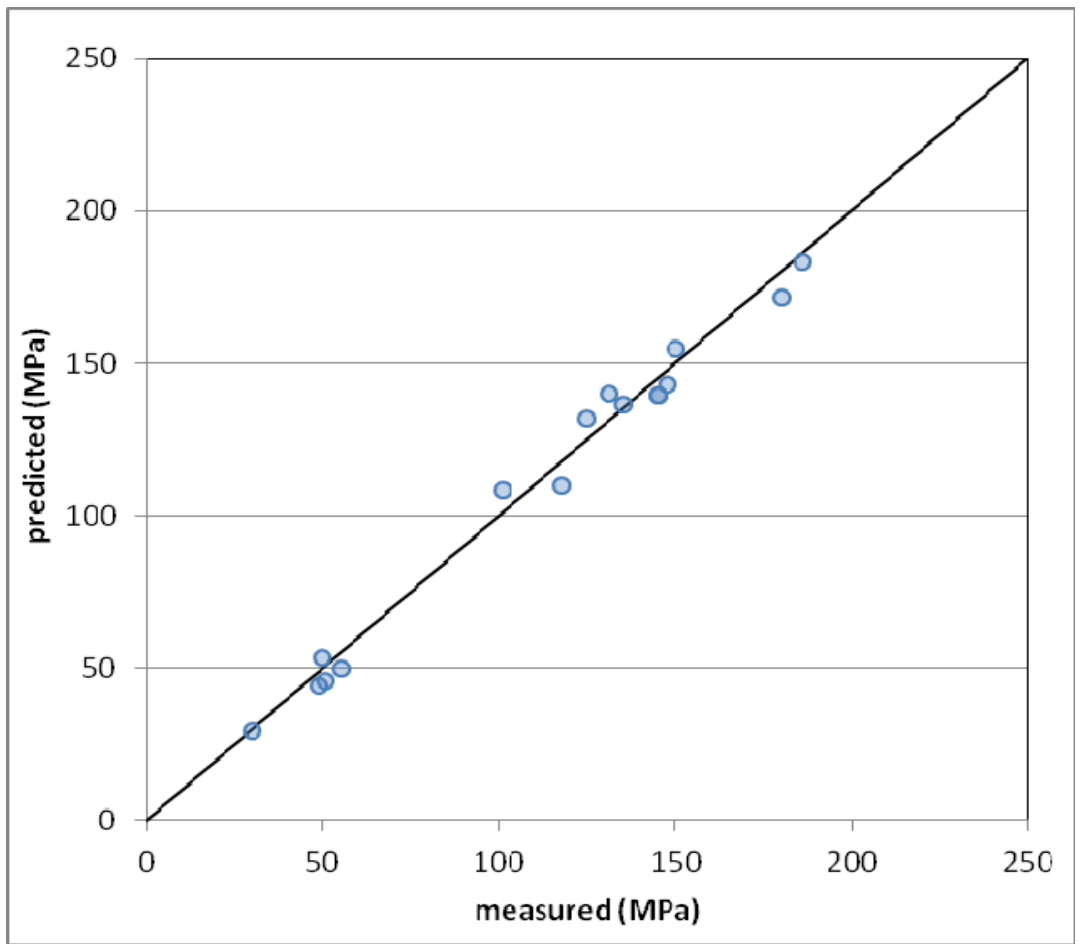

Fig. 8 Graph of predicted yield strengths considering co-clusters as the only cluster type, compared with reported yield strengths of alloys in this work and in [71] and data of commercially available alloys. (The median compositions of the composition ranges were adopted in the model.) 
To further evaluate the model, Fig. 9 shows the measured yield strength vs. model predictions of co-cluster content. The strength model predicts that the increase in strength with co-cluster content is dominated by the SRO strengthening effect, which is a linear function of co-cluster content. The data indeed show such a linear increase, which further supports the model. The data are not consistent with a square root dependency characteristic of classical precipitate strengthening mechanisms such as Orowan strengthening.

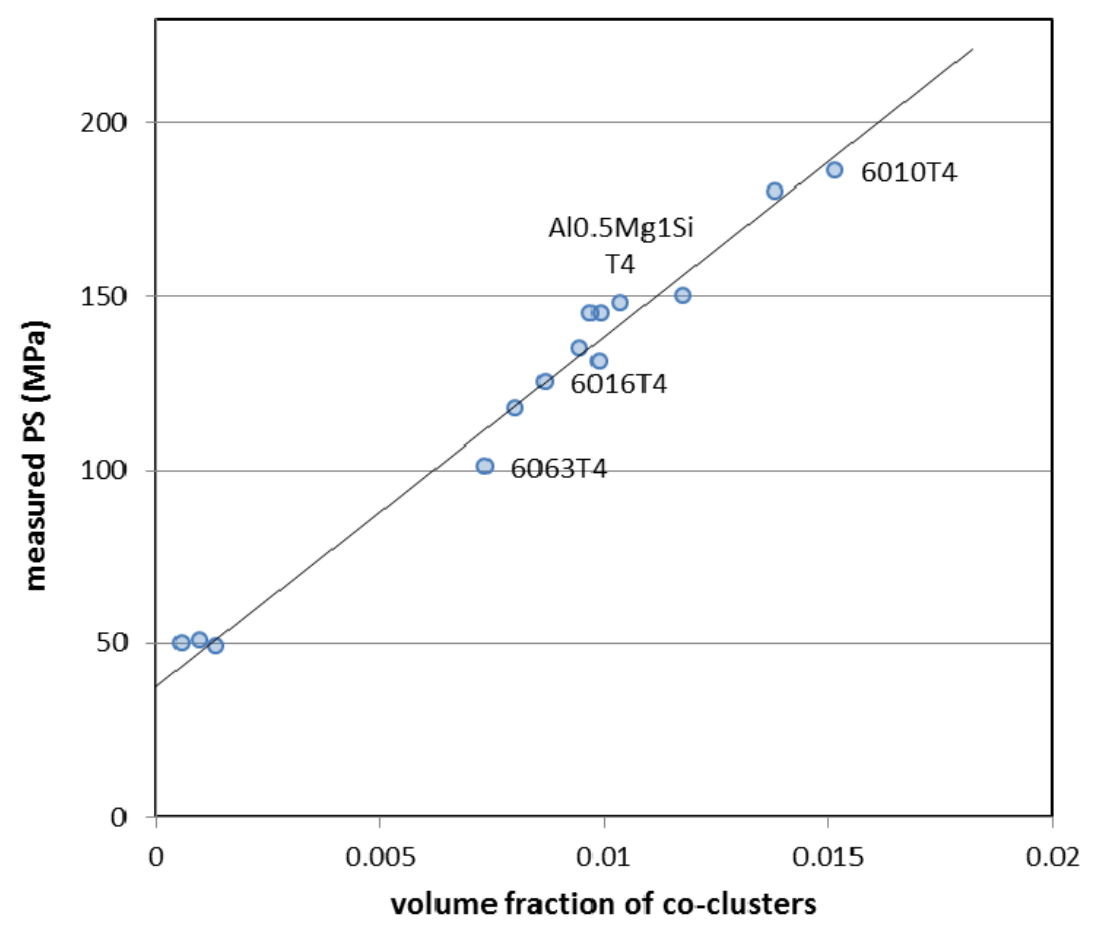

Fig. 9 Measured yield strength vs. predictions of co-cluster volume fraction using the thermodynamic model in Section 2.1.

\section{Discussion}

\subsection{Evaluation of 3DAP data on cluster composition}

Much of what we know about co-clusters rests on 3DAP data and the statistical analysis of that data. When 3DAP is performed on ternary alloys that contain co-clusters, generally a wide range of cluster sizes and compositions are detected, which may seem inconsistent with the present model. However, we need to consider two issues which influence this comparison. Firstly, the present thermodynamic model is based on interaction energies and the clusters are defined by the strong interactions between pairs of atoms, whilst in 3DAP analysis clusters are defined in a statistical sense determined by their detected locations. These can provide 
different interpretations of compositions and sizes of clusters. Secondly, experimental observations using 3DAP are strongly influenced by the limited detection efficiency in the 3DAP instrument, which is typically $50 \%$, and by the statistical analysis of the data. For instance, the 4-atom co-cluster structure in Fig 3 can in 3DAP analysis be assigned a range of cluster types: 2-atom $\mathrm{Si}-\mathrm{Si}, 2$-atom $\mathrm{Mg}$-Si, 3-atom $\mathrm{Si}-\mathrm{Mg}$-Si, 3-atom $\mathrm{Mg}$-Si-Mg, as well as the correct 4-atom configuration. In addition, cluster identification algorithms can assign two neighbouring clusters to one cluster if the distance between the two co-clusters is sufficiently small. To illustrate these issues, we have analysed the results of cluster identification for 3DAP data on a hypothetical M-A-B alloy considering a detection efficiency of $50 \%$ on all 3 atom types. We will here provide a simplified calculation of the probability of two neighbouring clusters being identified as one cluster by assuming that i) all clusters for which the center to center distance is less than the average length of the individual clusters will be classified as a single cluster, whilst other cluster pairs will always be identified as separate; ii. no atoms of one clusters can be in a near neighbour position to atoms from another cluster; elsewhere the average cluster density is homogeneous (equalling $\left(\mathrm{x}_{\mathrm{A}}+\mathrm{x}_{\mathrm{B}}\right) / 4$ for the present 4 atom co-clusters). This produces and estimate of $\sim 4\left(x_{\mathrm{A}}+x_{\mathrm{B}}\right)$ for the probability of two neighbouring clusters being identified as a single cluster. Results of this simulation are provided in Fig. 10. The insert in Fig. 10 shows a schematic diagram of two potential 4-atom clusters in close proximity. These results show that even though in the sense of interaction energies all clusters present are 4-atom co-clusters of the A-B-A-B type, an analysis of 3DAP data using a cluster location algorithm will detect a range of clusters types with sizes between 2 and 8 atoms. The composition will range from pure $\mathrm{A}$ to pure $\mathrm{B}$, and the spread of the composition ratio $\mathrm{A} /(\mathrm{A}+\mathrm{B})$ has a standard deviation of 0.25 .

The latter standard deviation is similar to that seen in a statistical analysis of 3DAP data on Al-Mg-Si samples containing clusters ( 0.31 for clusters larger than 3 solute atoms, and a total alloying atom fraction larger than 0.5 ). Hence, the composition spreads measured by 3DAP, rather than providing evidence for a wide variation in composition of clusters, may be consistent with the composition range of co-clusters being quite narrow. Fig. 10 shows that some of the spread of sizes can be an artefact induced by detection efficiency and statistical methods. Hence, caution is needed when assessing 3DAP data on cluster composition and cluster size. If we compare i) 3DAP data on Al-Mg-Si alloys in this and other works [6,7], ii) the present analysis of statistics related to identification of clusters and their sizes, and iii) the model in section 2, the most probable interpretation appears to be that co-clusters typically contain an even number of alloying atoms with the total number per cluster typically being around 2 to 16 .

In addition it is also relevant to note that quenched-in vacancies enhance the rate of the cocluster formation process by enhancing diffusion and they also can be incorporated in the coclusters $[14,72]$. But total amount of vacancies per volume unit is generally at least 2 orders 
of magnitude smaller than the amounts of solute atoms forming clusters / co-clusters, and hence these vacancies are expected to not have a significant influence on strengthening.

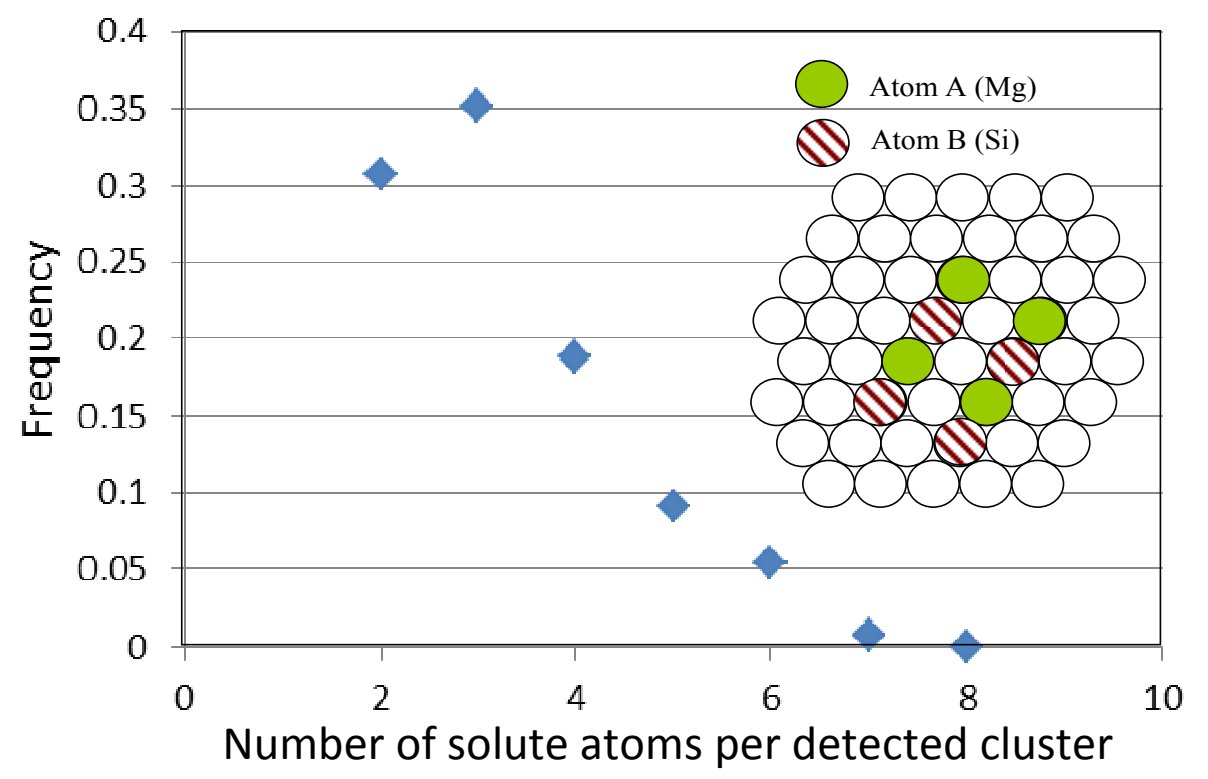

Fig. 10 Simulated results of 3DAP analysis of a material containing 4-atom co-clusters similar to those shown in the insert following a cluster identification algorithm. The 3DAP instrument detection efficiency is taken as 50\%. The graph shows the frequency of occurrence of clusters comprised of 2-8 solute atoms. The average composition $\mathrm{A} /(\mathrm{A}+\mathrm{B})$ of detected clusters is $0.5 \pm 0.25$ (standard deviation).

\subsection{Relation between co-clusters and $\beta^{\prime \prime}$}

The structure of the so-called pre- $\beta^{\prime \prime}$ precipitate proposed in [20] can be seen as an arrangement of $\mathrm{Mg}$-Si dimers, with small shifts in lattice positions with respect to the host $\mathrm{Al}$ rich fcc matrix. In that context, the formation of a dimer can be seen as the first stage of the formation of a pre- $\beta^{\prime \prime}$ precipitate, i.e. a dimer would be seen to be a 2-atom nucleus of a pre$\beta^{\prime \prime}$ precipitate. To develop into a precipitate, several dimers would need to be positioned in close proximity: dimers would need to coagulate to form areas that are highly enriched in solute atoms.

\subsection{Expanding the model to include both co-clusters and Si-Si clusters}

The model based on co-clusters in Section 2 has been successful in explaining enthalpy changes and the strength of a large database of Al-Mg-Si alloys, and the assessment of the effect of detection rate in 3DAP analyses can explain why some Si-Si clusters and some Mg- 
$\mathrm{Mg}$ clusters are detected. However, these cannot explain the observation that the average $\mathrm{Mg}: \mathrm{Si}$ ratio of very small clusters deviates from unity. Hence we will here present a modification that addresses these issues.

In the model modification we will add clusters of the type A-A (for instance Si-Si). Data on such clusters is limited, and thermal analysis results for solution treated and quenched Al-Si alloys show no exothermic peak in the early stages of precipitation [73]. It is possible that this can be due to Si clusters being formed very rapidly (within minutes after completion of the quench) and also having a low enthalpy of formation. In addition, the low numbers of atoms involved and the immediate start of the exothermic effect during thermal analysis can also conspire to cause any exothermic effect due to Si-Si clustering to be effectively undetectable.

We can construct a model for strengthening by Si clusters using some of the mechanisms outlined in Section 2. To provide a reliable model for strengthening by Si clusters, we would need data on the solvus of the clusters and the enthalpy of formation. However, neither is available: extensive DSC experiments on binary Al-Si alloys by several researchers $[74,75,76]$ have shown that any dissolution of Si clusters is not detectable. We can, however, use data on the small strengthening effect due to the pre-aging at room temperature of Al-Si alloys (about $11 \pm 4 \mathrm{MPa}$ [77]) with our model in Section 2.2 to estimate the bond enthalpy of the Si clusters, $\Delta H_{\mathrm{Si}-\mathrm{Si}}$. This provides $\Delta H_{\mathrm{Si}-\mathrm{Si}}=9 \pm 3 \mathrm{~kJ} / \mathrm{mol}$. In addition, we may consider that, like most precipitates, the solvus of the clusters can be approximated by a regular solution expression

$$
c_{A}=C \exp \left[\frac{-\Delta H_{M m A a B b}}{R T}\right]
$$

where $\Delta H_{\mathrm{MmAaBb}}$ is the enthalpy of formation of the complex per mole of units, and $C$ is a constant that is usually in the order of 0.01 to 1 .

Taking these points into consideration, we can now propose a model that is consistent with all experimental findings. The main points are as follows. On quenching Al-Si and Al-Mg-Si alloys to room temperature, some of the $\mathrm{Si}$ forms $\mathrm{Si}$ clusters within seconds at room temperature, but they are suppressed on quenching in brine at $-30^{\circ} \mathrm{C}$ and storage temperatures of $-196^{\circ} \mathrm{C}$. Taking $C=0.1$ provides that the solvus of Si clusters is about 0.2 at $\% \mathrm{Si}$ at room temperature and 0.5 at $\%$ at $170^{\circ} \mathrm{C}$. During linear heating of Al-Si alloys, a substantial part of the clusters are stable up to the start of formation of the stable Si precipitates, and combined with the low heat effect, this means that effectively Si cluster dissolution cannot be detected in a DSC. 3DAP on Al-Si and Al-Mg-Si alloys does, however, detect substantial amounts of Si clusters, both after room temperature ageing and after artificial ageing. Strengthening due to these Si clusters is very small and in most cases cannot be detected for at least two reasons: 
a) on quenching to or storage at room temperature most of the hardening is completed within seconds, and b) any addition of $\mathrm{Mg}$ and/or $\mathrm{Cu}$ will cause hardening by Si clusters to be negligible in comparison with other hardening reactions. Thus, only in $\mathrm{Cu}$ - and $\mathrm{Mg}$-free $\mathrm{Al}-\mathrm{Si}$ alloys quenched to iced brine temperatures can there be any chance of detecting the hardening.

Model predictions were performed using $\Delta H_{\mathrm{MmAaBb}}=\Delta H_{\mathrm{Si}-\mathrm{Si}}=9 \mathrm{~kJ} / \mathrm{mol}, C=0.1$ and assuming that of half of the $\mathrm{Si}$ that is supersaturated with respect to the solvus of the $\mathrm{Si}$ clusters (after completed co-cluster formation) forms $\mathrm{Si}$ clusters. Comparison with experimental strength data shows a good correspondence. (The prediction accuracy is virtually unchanged, with RMSE $=6 \mathrm{MPa}$.) In this model, the alloys are predicted to contain a substantial amount of Si clusters. For instance, for our Al- $0.5 \mathrm{Mg}-1 \mathrm{Si}$ alloy, about $20 \%$ of the $\mathrm{Si}$ present in the alloy will form Si clusters, whilst 50\% would form $\mathrm{Mg}$-Si co-clusters. Considering that a substantial fraction of the co-clusters will be misidentified as Si clusters (see Section 6.1), these predictions are now fully consistent with the 3DAP data. We may thus conclude that with this modification, the model is fully consistent with all strength, 3DAP, TEM and calorimetry data presented in or referred to in this paper.

The above analysis indicates that the 3DAP data on our naturally aged Al-Mg-Si alloy is consistent with clusters being predominantly $\mathrm{Mg}$-Si co-clusters with a $\mathrm{Mg}$ :Si ratio close to 1 and containing from 2 to 16 solute atoms. In addition, a significant number of Si-Si clusters appear to be present in this excess Si alloy. It is further relevant to note that when co-cluster formation in $\mathrm{Al}-\mathrm{Cu}-\mathrm{Mg}$ is studied by Nuclear Magnetic Resonance, it is found that during the hardening stage, one single and clearly defined peak appears in the spectrum [78]. This indicates that these co-clusters have a single clearly defined composition, even though 3DAP may suggest a wide range of compositions.

It is also observed that there is no particular correlation between residual error in the strength prediction and the $\mathrm{Mg}: \mathrm{Si}$ ratio of the alloys considered i.e. the model retains a consistent accuracy for both low and high $\mathrm{Mg}: \mathrm{Si}$ ratios. This further supports that strengthening is dominated by co-clusters with a Mg:Si ratio of 1 .

\subsection{Alternative models}

In the present thermodynamic model formulation the co-clusters are defined by enthalpy related to bonds between dissimilar alloying atoms. As a result, they contain an equal number of $\mathrm{Si}$ and $\mathrm{Mg}$ atoms and the total number of solute atoms is an even number. However, one might argue that $\mathrm{Mg}$ and $\mathrm{Si}$ atoms should diffuse separately to co-clusters with the aid of vacancies and hence at least in an intermediate state also co-clusters with an odd number of atoms should occur. Due to the relative amounts of atoms available, these odd numbered coclusters should have a composition that tends to the average alloy composition. As the co- 
clusters grow, however, they should approximate the 1:1 stoichiometry in the model. This is in fact what we are seeing when we investigate different alloys by 3DAP: the average $\mathrm{Mg} / \mathrm{Si}$ ratio of the smallest clusters in our $0.5 \mathrm{Mg}-1 \mathrm{Si}$ alloy is between 0.5 and 1 , while in a $1 \mathrm{Mg}$ $0.5 \mathrm{Si}$ alloy it is closer to 2 . It should be noted that within the present model, the addition of a single atom to an even numbered co-cluster would not cause a significant increase in the strength because the change in enthalpy is negligible.

We may also consider that whilst the present model is consistent with a wide range of experimental data and predicts strengths of the alloys to a high accuracy, we can as yet not prove that the enthalpy change of samples is determined only by near neighbour A-B bonds. This means that there may be other co-cluster types that can form the basis of a successful model. In further work one may thus consider producing a model containing co-clusters with both nearest neighbour and next-nearest neighbour interactions and analyse the thermodynamics and dislocation interactions. Such a model would be much more complex than the present one and would require one or more fitting parameters. Following the type of cluster-dislocation interactions considered in the present model (section 2.2) we expect that the short range order strengthening in any such model is approximated well by an expression of the type:

$$
\Delta \tau_{S R O} \cong C \frac{\Delta H_{\text {bond }}}{b^{3}}\left(y_{A}+y_{B}\right)
$$

where $\Delta H_{\text {bond }}$ is an effective average bond enthalpy in the co-cluster and $C$ is a constant of the order of unity. It is possible that such a model can also fit the data considered here, but it would be at the expense of computationally expensive modelling. One may also consider that clustered states are more dynamic than what is considered in the present model, with coclusters continuously forming, dissolving and changing throughout the ageing process. However, also in such a model, a relation of the type given in the latter equation can be expected.

\subsection{Relevance to impaired artificial ageing response}

The present study provides some useful insights into the mechanisms causing the impaired early-stage artificial ageing response of $\mathrm{Al}-\mathrm{Mg}$-Si based alloys with $\mathrm{Mg}_{2} \mathrm{Si}$ content in excess of $\sim 1 \mathrm{wt} \%$ following room temperature ageing, which is important for some industrial applications of these alloys (e.g. paint-baking of automotive body panels). Firstly, the present model clearly shows that the strengthening due to clusters and co-clusters is subject to a maximum, and at the maximum dissolvable $\mathrm{Mg}$ and $\mathrm{Si}$ contents, the yield strength is predicted to be $190 \mathrm{MPa}$. That maximum is well below what can be achieved by an optimised artificial ageing treatment. Once part of the $\mathrm{Si}$ and $\mathrm{Mg}$ has formed clusters and/or co-clusters, 
these atoms cannot contribute to significant further strengthening as long as they remain as clusters and co-clusters, and coarsening of clusters will not provide a significant strengthening effect. The size of the vast majority of co-clusters is well below the critical size for the nucleation of a $\beta^{\prime \prime}$ precipitate, and hence further hardening by nucleation and subsequent growth can only proceed if the co-clusters are dissolved. But as shown in the present model, the driving force for dissolution will be low as the solvus is very close to the artificial ageing temperature (see Fig. 2). Thus the dissolution of co-clusters will be sluggish, and as a result, hardening beyond the level reached during room temperature ageing will be sluggish.

This assessment points at one solution to improve the ageing response of the higher strength commercial 6xxx series alloys, which is to immediately age a quenched alloy at or near the standard artificial ageing temperature for a time that is sufficient to produce some viable $\beta^{\prime \prime}$ nuclei. On continued artificial ageing (possibly after some intermediate natural ageing), these nuclei would then be available for $\beta^{\prime \prime}$ growth, and the dissolution of any co-clusters that may exist can then proceed directly by the diffusion of $\mathrm{Si}$ and $\mathrm{Mg}$ atoms to the growing $\beta^{\prime \prime}$ nuclei. By contrast, any natural ageing before artificial ageing (i.e. after quenching) results in a poor early-stage ageing response because the co-clusters formed during natural ageing consume solute, do not effectively nucleate $\beta^{\prime \prime}$ and only dissolve sluggishly at the ageing temperature. Any natural ageing between quenching and artificial ageing should therefore be avoided if a rapid early-stage ageing response is required.

\section{Conclusions}

An expanded thermodynamic model for co-clusters and a model for the strengthening due to these co-clusters is presented, and applied to the natural ageing of 6xxx series aluminium alloys. The model includes a treatment of (short-range) order strengthening relevant to these co-clusters. The model is tested against data on Al-Mg-Si alloys. It is shown that:

- The thermodynamic model is consistent with data on the heat evolution due to co-cluster formation. The Mg-Si interaction enthalpy, $\Delta H_{\mathrm{Mg}-\mathrm{Si}}$, is determined as $28.6 \mathrm{~kJ} / \mathrm{mol}$.

- The metastable solvus for co-clusters in Al-Mg-Si alloys is calculated.

- The model is successfully tested against data on proof strength for a wide range of Al-Mg-Si alloys aged at room temperature.

- Extensive 3DAP data on room temperature aged samples of an Al-0.5Mg-1Si alloy are investigated. These data show that extensive cluster formation occurs during natural ageing. The data are consistent with the model, i.e. clusters being predominantly $\mathrm{Mg}$-Si co-clusters with a Mg:Si ratio close to 1. Comparison of 3DAP data with model predictions, whilst taking into account statistics related to the identification of clusters, indicates that co-clusters formed during natural ageing typically contain about 2 to 16 solute atoms.

- Co-cluster formation causes strengthening increments that are in good approximation proportional to the change in enthalpy of the alloy. 
- Co-cluster strengthening of the type that occurs in the present alloys is proportional to the amount of co-clusters that is formed, and is thus very different from most classical strengthening mechanisms which have a square-root of volume fraction dependency.

\section{Acknowledgements}

Dr Zhihua Zhu is gratefully acknowledged for additional tensile testing and additional EDS analyses. Dr Dacian Tomus is thanked for providing Fig. 11. Helpful discussions with Dr Malcolm Couper are also gratefully acknowledged. In addition, the authors would like to thank the Aluminium Corporation of China Ltd. (CHALCO) for providing the Al- $0.5 \mathrm{Mg}-1 \mathrm{Si}$ alloy and supporting some aspects of this work financially. Use of the 3DAP facilities at the Monash Centre for Electron Microscopy (MCEM) is also gratefully acknowledged.

\section{Appendix: Undissolved intermetallics}

Insoluble or undissolved intermetallic particles and dispersoids, such as $\beta-\mathrm{Al}_{5} \mathrm{FeSi}, \alpha-$ $\mathrm{Al}_{15}(\mathrm{FeMn})_{3} \mathrm{Si}$ and $\alpha-\mathrm{Al}_{12}(\mathrm{Fe}, \mathrm{Mn})_{3} \mathrm{Si}$, which form during solidification or homogenisation, can be present in $\mathrm{Al}-\mathrm{Mg}-\mathrm{Si}$ type alloys with $\mathrm{Mn}$ and $\mathrm{Fe}$ additions and impurities $[67,79,80,81,82,83,84]$. The SEM micrograph in Fig. 11 reveals their presence in our Al$0.5 \mathrm{Mg}-1 \mathrm{Si}$ alloy in the solution treated condition, and EDS analysis confirmed the presence of $\mathrm{Si}$ in them. Since the presence of these phases will remove some Si from the solid solution, it is necessary to calculate the effective solute concentration in the matrix after solution heat treatment. The solubility of $\mathrm{Mn}$ and Fe during solution treatment has been studied and predictions using thermodynamic modelling are available [79]. We will here use these predictions to estimate the amount of $\mathrm{Si}$ in solution. We performed additional thermodynamic modelling using Thermocalc with the COST database to provide further confirmation.

As the solubility of Fe and $\mathrm{Mn}$ is much lower than the amounts encountered in the modelled alloys, we will effectively assume all Fe and $\mathrm{Mn}$ forms intermetallic particles. Yoo et al. [83] studied the relation between the size, Mn:Fe ratio and crystal structure of AlMnFeSi particles in an $\mathrm{Al}-0.50 \mathrm{Mg}-0.65 \mathrm{Si}-0.20 \mathrm{Mn}-0.12 \mathrm{Fe}-0.034 \mathrm{Cu}$ alloy and showed that for particles with $\mathrm{Mn}: \mathrm{Fe}$ ratios of $>1.6$, the structure was simple cubic and the particles were isomorphous to the $\mathrm{Al}_{15}(\mathrm{Mn}, \mathrm{Fe})_{3} \mathrm{Si}_{2}$ phase, while at lower $\mathrm{Mn}$ :Fe ratios, the phase was body centred cubic and isomorphous with $\alpha-\mathrm{Al}_{12}(\mathrm{Fe}, \mathrm{Mn})_{3} \mathrm{Si}$. In line with this, Thermocalc predictions of the equilibrium Al-Mn-Fe-Si phase diagram at typical solution treatment temperatures also indicate a shift to phases with a higher $(\mathrm{Fe}+\mathrm{Mn})$ :Si ratio with reducing $\mathrm{Mn}: \mathrm{Fe}$ in the alloy. In solution treated alloys with $\mathrm{Si}: \mathrm{Mg}=1$, most intermetallics have a $(\mathrm{Fe}+\mathrm{Mn}): \mathrm{Si}$ ratio of 1.5, regardless of whether the Mn content is lower than the Fe content [82] or substantially higher than the Fe content [53]. We incorporate these findings in our model. (The present model could be further improved by modelling the amount of intermetallics and the amount of Si in 
solution during solution treatment in more detail, but this is considered out of the scope of the present work. Changes in the method of approximating Si content in intermetallics, such as changing $(\mathrm{Fe}+\mathrm{Mn})$ :Si from 1.5:1 to 3:1, typically changes strength predictions by about 1 to 5 $\mathrm{MPa}$.)

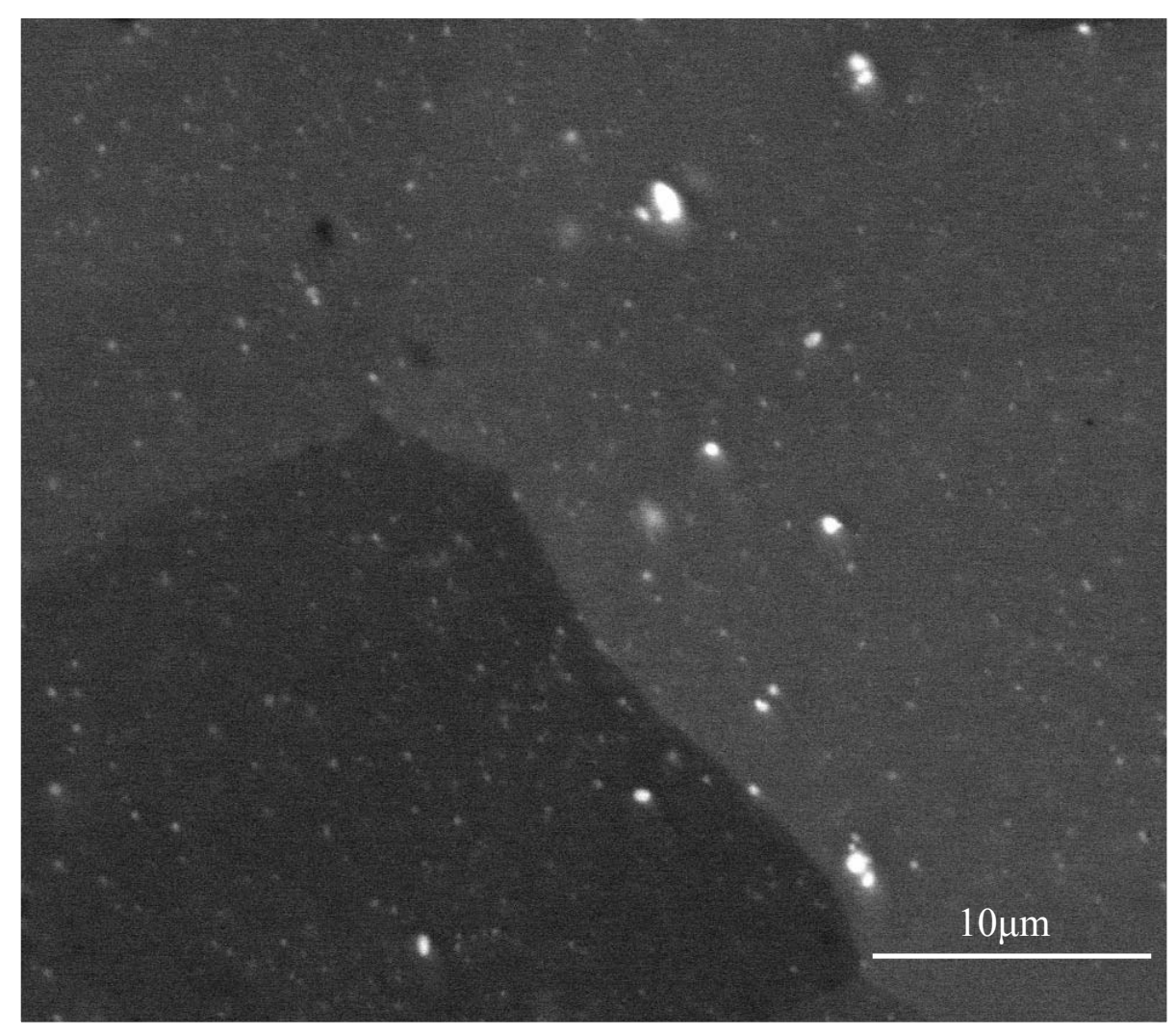

Fig. 11 Backscattered SEM micrograph of the Al-0.5Mg-1Si alloy in the solution treated condition $\left(0.5 \mathrm{~h}\right.$ at $550^{\circ} \mathrm{C}$, followed by quenching), showing intermetallic particles $(0.5-2 \mu \mathrm{m})$ and finer dispersoid particles. These particles show up bright in the backscattered mode due to the presence of higher atomic number elements ( $\mathrm{Fe}, \mathrm{Mn}$ ). 


\section{References}

1 Pereloma EV, Shekhter A, Miller MK, Ringer SP. Acta Mater 2004,52:5589.

2 Pereloma EV, Timokhina IB, Russell KF, Miller MK. Scripta Mater 2006, 54:471.

3 Stephenson LT, Moody MP, Liddicoat PV, Ringer SP. Microsc \& Microanal 2007,13:448

4 Honma T, Yanagita S, Hono K, Nagai Y, Hasegawa M. Acta Mater 2004, 52:1997

5 Edwards GA, Stiller K, Dunlop GL, Couper MJ, Acta Mater 1998, 46:3893-3904.

6 Murayama M, Hono K, Acta Mater 1999, 47: 1537-1548.

7 Serizawa A, Hirosawa S, Sato T, Metall Mater Trans A 2008, 3: 243-251

8 Rometsch PA, Cao LF, Xiong XY, Muddle BC, Ultramicroscopy 2011, 111: 690-6941

9 Sha G, Marceau RKW, Gao X, Muddle BC, Ringer SP, Acta Mater 2011, 59: 1659

10 Starink MJ, Gao N, Davin L, Yan J, Cerezo A. Phil. Mag. 2005, 85: 1395

11 Wang SC, Starink MJ. Int Mater Rev. 2005, 50:193

12 Bastow TJ, Phil.Mag. 2005, 85: 1053

13 Bastow TJ, Hill AJ. Mater. Sci. For. 519-521: 1355-1360, 2006.

14 Staab TEM, Haaks M, Modrow H. Appl Surf Sci 2008, 255: 132-135.

15 Klobes B, Staab TEM, Haaks M, Maier K, Wieler I. Phys Stat Sol 2008, 2: A61 - A66.

16 Banhart J, Lay MDH, Chang CST, Hill AJ, Phys Rev B 2011, 83: 014101.

17 Pogatscher S, Antrekowitsch H, Leitner H, Ebner T, Uggowitzer P, Acta Mater 2011, 59: 3352-3363.

18 Buha J, Lumley RN, Crosky AG, Hono K, Acta Mater 2007, 55: 3015-3024

19 Marioara CD, Andersen SJ, Jansen J, Zandbergen HW, Acta Mater 2003, 51: 789-796.

20 Marioara CD, Andersen SJ, Jansen J, Zandbergen HW. Acta mater, 49 (2001), p. 321.

21 Buha J, Lumley RN, Crosky AG: Phil Mag 2008, 88: 373-390

22 Starink MJ, Wang SC, Acta Mater. 2009, 57: 2376.

23 Chang CST, Banhart J, Metall Mater Trans A, 2011, 42A:1960-1964

24 Feufel H, Godecke T, Lukas HL, Sommer F, J. Alloy. Compd. 1997, 247: 31-42.

25 Zhang H, Wang Y, Shang SL, Ravi C, Wolverton C, Chen LQ, Liu ZK, Calphad 2010, 34: $20-25$.

26 Kubaschewski O, Villa H, Z. Electrochem. 1949, 53: 32-40

27 Ardell AJ, Metall. Trans. A, 1985, 16: 2131

28 Nembach E. Phys. Stat. Sol. A, 1983, 78: 571

29 Büchner AR, Pitsch W. Z. Metallkde 1985, 76: 651.

30 Flinn, PA. Acta Metall 1958, 6: 631

31 Kostorz G. Schonfeld B. Chimia 2001,55:517

32 Khan IN, Starink MJ, Yan JL. Mater Sci Eng A 2008, 472: 66

33 Starink MJ, Deschamps A, Wang SC. Scr Mater, 2008, 58: 377

34 Hansen N. Acta Metall 1977;25:863

35 Engler O, Crumbach M, Li S, Acta Mater 2005, 53: 2241-2257.

36 Chawla KK, Composite materials: science and engineering, Springer, New York, 1998.

37 Ramakrishnan N. Acta Mater 1996, 44: 69-77.

38 Zhang Q, Chen DL. Scripta Mater 2004, 51: 863-867.

39 Zhu Z, Starink MJ. Mater. Sci. Eng. A 2008, 489:138.

40 Wang SC, Zhu Z, Starink MJ, J. Microscopy 2005, 217: 174-178.

41 Leyson GPM, Curtin WA, Hector LG, Woodward CF, Nature Mater. 2011, 9: 750-755.

42 Hidnert P, Krider HS: J. Research of the National Bureau of Standards 1952, 48: 2308.

43 Totemeier TC, Wright RN, Swank WD, Intermetallics 2004, 12: 1335-1344.

44 Chen CL, Richter A, Thomson RC, Intermetallics 2009, 17: 634-641.

45 www.asm.matweb.com, Oct 27, 2011

46 www.efunda.com, Oct 27, 2011

47 Davis JR (ed), ASM Specialty Handbook: Aluminum and Aluminum Alloys, 1993, ASM International, Materials Park, OH, USA

48 Kutz M (ed), Handbook of Materials Selection, 2002, Wiley, London, UK

49 Kaufman JG, Introduction to aluminum alloys and tempers, ASM International, Materials Park, OH, USA (2000)

50 Chandler H, Heat treater's guide: practices and procedures for nonferrous alloys, ASM International, Materials Park, OH, USA (1996)

51 Brandes EA, Brook GB (eds), Smithells light metals handbook, 1998, Butterworths Heinemann, Oxford, UK

52 Marchive D, Light Metal Age (1983) 4-10

53 Quaino GK, Yannacopoulos S, Ghana J. Sci. 2007, 47:, 91-100 
54 Haga T, Ikawa M, Watari H, Kumai S, J. Achievements in Materials Manufacturing Engineering 2006, 18: 371

55 Chang CST, Wieler I, Wanderka N, Banhart J, Ultramicroscopy 2009, 109: 585-592

56 Yan-li Ji, Fu-an Guo, Yan-feng Pan, Trans Non-Ferr Met Soc China 18 (2008) 126-131

57 Mulazimoglu MH, Drew RAL, Gruzelski JE. J. Mater. Sci. Lett. 1989, 8: 297-300

58 Cuniberti A, Tolley A, Castro Riglos MV, Giovachini R, Mater Sci Eng A 2010, 527: 5307-5311.

59 Clausen B, Lorentzen T, Leffers T. Acta Mater 1998, 46: 3087.

60 Starink MJ, Wang SC, Acta Mater 2003, 51: 5131-5150.

61 Qiao XG, Starink MJ, Gao N, Acta Mater 2010, 58: 3690-3700

62 Fjeldly A, Roven HJ, Acta Mater 1996, 44: 3497-3504.

63 Hargarter H, Lyttle MT, Starke EA, Mater Sci Eng A, 1998, 257: 87-99.

64 Juul Jensen D, Hansen N, Acta Metall Mater 1990, 38: 1369-1380.

65 Lee NH, Chen JH, Kao PW, Tseng TY, Su JR, Mater Sci and Engineering: A, Volume 528, 2011, Pages 1979-1986.

66 Hatch JE, Aluminum: properties and physical metallurgy, American Society for Metals, Materials Park, OH, USA (1984)

67 Mondolfo LF, Structure and Properties of Aluminium Alloys, Butterworth, London, UK (1976).

68 Leyson GPM, Curtin WA, Hector LG, Woodward CF, Nature Mater 2010, 9:750-755

69 Zhu Z, Starink MJ. Mater. Sci. Eng. A 2008, 489:138.

70 Wang SC, Zhu Z, Starink MJ, J. Microscopy 2005, 217: 174-178.

71 Birol Y, Mater Sci Eng A 2005, 391: 175-180.

72 Klobes B, Maier K, Staab TEM, Mater Sci Eng A 2011, 528: 3253-3260

73 Gupta AK, Lloyd DJ, in Aluminium Alloys: Their Physical and Mechanical Properties, Vol. 2, ed. L. Arnberg et al.. Norwegian Inst of Techn. and SINTEF Metallurgy, Trondheim, Norway, 1992, p. 214.

74 Hälldahl L, Thermochim. Acta 1993, 214: 33.

75 Lasagni F, Mingler B, Dumont M, Degischer HP, Mater Sci Eng A 2008, 480: 383-391

76 Starink MJ, Zahra AM, Philos. Mag. A 1998, 77: 187-199.

77 Rosenbaum HS, Turnbull D, Acta Metall 1958, 6: 653-659.

78 Deschamps A, Bastow TJ, de Geuser F, Hill AJ, Hutchinson CR. Acta Mater 2011, 59: 2918.

79 Kuijpers NCW, Vermolen FJ, Vuik C, Koenis PTG, Nilsen KE, van der Zwaag S, Mater Sci Eng A, 2005, 394: 9-19.

80 Kuijpers NCW, Tirel J, Hanlon DN, van der Zwaag S, Mater. Char. 2002, 48: 379-392.

81 Dons AL, Z. Metallkd. 1986, 77: 126-130

82 Couper MJ, Cooksey M, Rinderer B, in 'Aluminium Cast House Technology VII', Whiteley P, Grandfield J (eds), TMS, 2001, pp. 297-304

83 Yoo JE, Shan AD, Moon IG, Maeng SJ, J Mater Sci 1999, 34: 2679-2683

84 Strobel K, Sweet E, Easton M, Nie J, Couper M, Mater Sci Forum 2010, 654-656: 926-929. 